\title{
FELICIDAD, BIENESTAR SUBJETIVO Y SATISFACCIÓN EN LA SOCIEDAD GALLEGA
}

José Atilano Pena López José Manuel Sánchez Santos

\subsection{INTRODUCCIÓN}

En los últimos 25 años ha surgido un interés creciente en el estudio de la felicidad desde la perspectiva del bienestar subjetivo por parte de las ciencias sociales. La investigación sobre esta temática se ha desarrollado tanto en el campo de la Psicología (Kahneman et al., 1999), como de la Sociología (Venhoveen, 1993) y muy particularmente de la Economía (Bruni, 2004 y 2005; Frey y Stutzer, 2000 y 2002). En la mayoría de estos trabajos subyace como trasfondo común la pretensión de explicar desde diversos enfoques metodológicos las condiciones que permiten a los individuos desenvolverse como personas felices, socialmente implicadas y miembros de comunidades más prósperas y satisfechas.

Los imaginarios colectivos que caracterizaron el desarrollismo partían de la creencia de que mayores niveles de riqueza y de renta configuraban una realidad social con unas condiciones de vida mejores, mayor bienestar y, por extensión, mayor felicidad. Dicho de otra manera, la ciencia económica tendía a asumir que el bienestar material es una condición previa de la satisfacción subjetiva y que los cambios en la "felicidad" están directamente relacionados con los cambios en el poder adquisitivo. La aceptación de este supuesto tenía claras implicaciones en los planteamientos de las políticas económicas y sociales, de tal modo que la evolución del PIB constituía el objetivo prioritario de las mismas. No obstante, una amplio conjunto de estudios desarrollados bajo la denominación genérica de "paradojas de la felicidad" ponen en duda la validez de dichas hipótesis de partida. Concretamente, sería lógico pensar que la mejora del bienestar económico en términos diacrónicos no condujese a incrementos paralelos en los niveles de felicidad de la misma magnitud, pero no la constancia de los mismos, ni, por supuesto su disminución. La existencia de relaciones de trade off o intercambio entre ambos objetivos (renta y felicidad) es lo que ha venido a denominarse "paradoja de Easterlin" (Easterlin, 1974), y pone en cuestión buena parte de los 
supuestos tradicionales de la Economía. Esta evidencia disonante subraya la necesidad de analizar la felicidad y sus determinantes desde una perspectiva más amplia que la habitual, así como la incorporación de la misma a los fines últimos de la política económica ${ }^{1}$.

En el presente trabajo, a partir de las propuestas de lo que se ha dado en llamar "Economía de la Felicidad", planteamos una visión más holística de los factores influyentes en esta variable que identificamos con el bienestar subjetivo revelado. Concretando, a nivel empírico y tomando como base los resultados de la Encuesta Mundial de Valores para Galicia proponemos la construcción de una función microeconométrica que incorpore aquellos factores explicativos de la felicidad. Al mismo tiempo, analizaremos la evolución de los niveles de satisfacción subjetiva revelada (felicidad) y sus determinantes para obtener una visión general de la sociedad gallega. En definitiva, la vinculación de las diferencias interindividuales a las características sociodemográficas nos permitirá encontrar factores potencialmente explicativos de la configuración de dicha experiencia a través de sus determinantes biológicos (edad, personalidad...), estructura social (posición en las jerarquías, redes de pertenencia, nivel de renta...) y fuerzas sociales (libertad, capacidades, oportunidades vitales...). Adicionalmente, la pregunta que cabe plantearse es si la evolución de la percepción de la felicidad por la sociedad gallega se ajusta a las predicciones de la paradoja de Easterlin, es decir, se trata de verificar si se observa una tendencia al estancamiento en los niveles de bienestar paralela al incremento en los niveles de renta.

La estructura de este capítulo se puede resumir como sigue. En el siguiente apartado se procede a una delimitación del concepto de felicidad junto con la correspondiente justificación de la utilización del bienestar subjetivo revelado como indicador básico para el posterior análisis estadístico-econométrico. A continuación se aborda la naturaleza paradójica de la relación entre renta y felicidad, así como las posibles explicaciones de la misma. Posteriormente se propone una visión más holística del concepto de felicidad. Esta revisión nos permite fundamentar la construcción de una función que identifique los principales determinantes de la felicidad a partir de los datos extraídos de la EMV en su oleada del 2008 en Galicia. Para concluir, a modo de corolario del modelo general, se ahonda en las relaciones observadas entre felicidad y sus variables explicativas a lo largo del período que abarca el estudio (1995-2008). Finalmente, se resumen las principales conclusiones.

El último ejemplo que constituye un claro exponente de los intentos de buscar alternativas a la medición del bienestar o incluso de la felicidad (una noción que en algún momento parecía absurdo cuantificar) es la publicación del Report by the Commission on the Measurement of Economic Performance and Social Progress, publicado el 14 de septiembre de 2009, coordinado por J. Stiglitz, A. Sen y J. P. Fitoussi y que fue elaborado por una comisión formada por 25 destacados científicos sociales entre los que se incluyen 5 premios Nobel de Economía 


\subsection{FELICIDAD: CONCEPTO Y MEDICIÓN}

Como punto de partida de nuestro análisis se impone el realizar algunas precisiones conceptuales con el fin de evitar la confusión que se puede derivar de la plena equiparación de conceptos entre los que existe un vínculo evidente, pero que no son sinónimos: calidad de vida, bienestar y felicidad.

La calidad de vida alude a "la percepción que un individuo tiene de su lugar en la existencia, en el contexto de la cultura y del sistema de valores en los que vive y en relación a sus objetivos y expectativas, sus normas y sus inquietudes. Se trata de un concepto muy amplio que está influido por la salud física del sujeto, su estado psicológico, su nivel de independencia, sus relaciones sociales, así como su relación con los elementos esenciales de su entorno" (WHOQOL Group, 1995). En esta línea, el Programa de las Naciones Unidas para el Desarrollo (PNUD) viene calculando el Índice de Desarrollo Humano, basado en los trabajos de A. K. Sen (1999). Este indicador estadístico, introduce variables en las tres dimensiones que se han revelado como esenciales: renta, educación y salud. Ahora bien, si desgranamos la definición previa debemos distinguir dentro del concepto de calidad de vida dos vertientes: la presencia de las condiciones consideradas necesarias para una vida buena y la práctica del vivir en cuanto tal. La calidad de vida a escala social solo puede entenderse bajo el prisma del primero de los significados. En cambio, si la aplicamos a escala individual el término puede usarse en ambas acepciones: disfrutar de las condiciones adecuadas en una vida realizada. Esto nos lleva directamente a las valoraciones individuales sobre las condiciones personales de vida como indicador social, esto es, el problema del bienestar subjetivo y la felicidad.

El concepto de bienestar es un constructo abstracto con connotaciones subjetivas, pero que está correlacionado con factores económicos objetivos. Así, el bienestar individual alude a la conciencia que tiene cada individuo de haber cubierto sus necesidades privadas. Por su parte, el bienestar social estaría originado por el hecho de que un elevado porcentaje de los individuos, que se integran en un determinado grupo social, satisfagan sus necesidades. En la medida en que esta noción de bienestar tiende a sustentarse en perspectivas de corte individualista y subjetivo, se puede aproximar a través de la percepción o valoración que los sujetos hacen de sus propias vidas. A su vez, dentro de esta percepción general se distinguen varias dimensiones del bienestar subjetivo: bienestar económico, bienestar psicológico y bienestar social. En cada una de estas vertientes se resalta la valoración que el individuo realiza de su situación económica, de los estados afectivo-emocionales y psicológicos o de su funcionamiento social, respectivamente.

Uno de los objetivos sociales en la mayor parte de las economías avanzadas es lograr progresos en lo que denominamos Estado del Bienestar. Sin embargo, esta expresión induce a una importante confusión, ya que traduce la inglesa 
welfare que no es directamente equivalente, sino que se refiere a la sensación de seguridad o placer derivada de tener cubiertas buena parte de las carencias o necesidades sentidas, de modo que nos estaríamos refiriendo, más concretamente, a un Estado benefactor en la medida en que éste garantice unas necesidades básicas mediante un conjunto de actuaciones. El bienestar subjetivo (wellbeing), en cambio, alude a una valoración que del bienestar personal hace un sujeto vía encuesta.

En cuanto a la noción de felicidad, el primer problema que se plantea es la definición de lo que ésta constituye propiamente. En este sentido, Easterlin $(1995,2001)$ establece, como vía de simplificación, una identidad entre la felicidad y el bienestar subjetivo revelado o satisfacción expresada.

En general, para los economistas la palabra felicidad o bienestar subjetivo no es más que una valoración de la propia vida en sí misma, al margen de los juicios psicológicos sobre el placer momentáneo, esto es, hace referencia a cómo el individuo evalúa la calidad global de su vida (Veenhoven, 2000). Consecuentemente, el posicionamiento de los individuos dependerá íntegramente de una percepción individual $^{2}$ y está ligado directamente a los dos conceptos previos de calidad de vida y bienestar.

La Psicología por su parte, huyendo de las simplificaciones, ha tratado de delimitar las diversas dimensiones que componen el complejo que denominamos "felicidad". Esto le lleva a distinguir un componente cognitivo de autopercepción de la satisfacción vital, una dimensión afectiva o de vínculos relacionales del individuo y el bienestar subjetivo. Este último se identifica con un estado de bienestar general y permanente que incluye las dimensiones afectiva y cognitiva y sería, por tanto, sintético e identificable con la noción más estricta de felicidad (Ahuvia y Friedman, 1998). Ahora bien, en sentido estricto se pueden establecer diferencias entre la felicidad y la satisfacción subjetiva. Si bien la felicidad, al igual que la satisfacción, es una apreciación subjetiva de un individuo sobre su propia vida, la primera tiene una carga afectiva relativamente mayor (Argyle, 2002). No obstante, a pesar de las mencionadas diferencias, ambas variables manifiestan una elevada correlación.

En suma, la felicidad es un concepto más exigente e íntimo que el bienestar subjetivo y que la calidad de vida. Se trata de un estado personal extremadamente difícil de concretar, pero tal y como plantean Nussbaum y Sen (1993), es recomendable evitar el relativismo absoluto para converger en aquellas dimensiones de la vida que permitan aflorar lo que se suele considerar plenamente humano (educación, salud, libertad...). La realización humana conlleva el acceso a unos bienes materiales, a una educación, a una red de relaciones, para poder llevar el tipo de vida que, por la razón que sea, deseamos. Este progreso en la realización

Este punto la convierte en objeto de crítica por buena parte de los economistas neoclásicos e incluso algunos de orientación humanista (Sen). 
personal o humana redunda, como veremos, tanto en términos de felicidad como de libertad o dominio de la propia vida. Expresado de un modo simplificado, entendemos por felicidad sentirse bien, disfrutar de la vida y desear que ese sentimiento se mantenga. Por el contrario, aquellos que se manifiestan como poco felices revelan el deseo de un cambio decisivo de situación.

En principio, y de acuerdo con las anteriores consideraciones, podría pensarse que la felicidad, en la medida en que se trata de algo individual y propio de las circunstancias de cada sujeto, es algo que solo tangencialmente corresponde al análisis social. Sin embargo, si se reflexiona sobre los elementos intersubjetivos es posible delimitar un campo de análisis en donde los individuos son los mejores jueces sobre su situación personal.

A estos efectos, la Encuesta Mundial de Valores ofrece una amplia serie de indicadores de bienestar subjetivo o de felicidad revelada que resultan esclarecedores en tanto que permiten una cierta aproximación a la evaluación global que los individuos realizan de sus circunstancias personales y de toda la sociedad en su conjunto.

La citada encuesta constituye un referente contrastado esencial para el análisis de la evolución de las percepciones valorativas de cualquier sociedad. En la actualidad se dispone de una muy amplia base de datos a escala internacional (80 países) para un período superior a 25 años en oleadas de cinco años. Para el caso gallego, en el que nos centraremos, disponemos ya de tres oleadas $(1995,2001,2008)$ lo que nos permite tener una perspectiva temporal lo suficientemente amplia para analizar las trasformaciones socioeconómicas habidas en el último período ${ }^{3}$. En lo relativo a las variables en las que centraremos nuestro análisis empírico, la felicidad y satisfacción en sus diversos niveles queda recogida en un conjunto de cuestiones categóricas ordinales. Así, por ejemplo, la felicidad es abordada a través de la cuestión (v10) ¿Diría usted que es...". A esta cuestión caben cuatro respuestas gradadas: muy feliz, bastante feliz, no muy feliz y nada feliz.

Respecto a las dudas que pudieran surgir sobre la validez de las respuestas a este tipo de preguntas, hay que tener en cuenta que los individuos son conscientes de cómo se sienten ellos mismos y, además, la empatía les dota de la capacidad de analizar cómo se sienten los demás. Adicionalmente, conviene subrayar que los individuos, al responder a este tipo de preguntas, adoptan visiones de largo plazo. Es decir, implícitamente están considerando la situación media o las sensaciones permanentes. Por otra parte, al tratar la felicidad como una variable con una dimensión única, los individuos pueden situarse dentro de un continuum reflejando como se encuentran respecto a su vida en conjunto.

El universo de la EMV-Galicia es la población gallega mayor de 18 años. El tamaño muestral es 1.200 entrevistas (error muestral 2,9\%). 
Este sistema por el que optamos, por tanto, frente a las tradiciones de imputación y apriorísticas, como es el mismo $\mathrm{IDH}^{4}$, constituye una alternativa en la que se prioriza la valoración que el propio individuo realiza de su vida. Se trata de un enfoque propio del individualismo metodológico ya que, tanto la concepción del bienestar, la medición del mismo y los presupuestos dan la primacía a la propia valoración individual del bienestar. En definitiva, la investigación sobre las fuentes del bienestar individual revelado exige asumir un simple supuesto: que los individuos son capaces de evaluar su utilidad tomando en consideración sus circunstancias individuales, su posición respecto a otros, su experiencia pasada y sus expectativas de cara al futuro.

\subsection{LA NATURALEZA PARADÓJICA DE LA RELACIÓN ENTRE FELICIDAD E INGRESOS}

La relación entre riqueza, satisfacción y felicidad se ha convertido en una de las líneas esenciales de investigación en el campo de la socioeconomía. Desde una perspectiva puramente económica, la relación de la felicidad con la renta y el crecimiento económico ha resultado un tema, cuando menos, controvertido. En concreto, la evidencia empírica general sugiere una pérdida de significatividad del crecimiento económico y de la renta como variables determinantes de la felicidad, lo cual requiere ser explicado ${ }^{5}$.

Aunque pueda parecer más o menos evidente que el dinero no da la felicidad, el análisis económico tiende a asumir el axioma de la no saturación, que en su formulación más simple consiste en afirmar que siempre hay un bien para el que es preferible tener más que menos. Consecuentemente, los individuos con más renta real pueden acceder a paquetes de bienes superiores, lo que les permitiría mejorar en su nivel de bienestar. Sin embargo, los estudios realizados para un amplio conjunto de países arrojan resultados un tanto contraintuitivos.

Por ejemplo, la tendencia dominante en los EE. UU. y Japón es hacia la estabilización o incluso al leve decrecimiento de los niveles de bienestar subjetivo percibido y para las más importantes economías europeas se aprecian leves incrementos y en algún caso también estancamiento y reducción con escasa significatividad estadística (DiTella et al., 1999). En general, las poblaciones de sociedades más ricas revelan niveles de bienestar subjetivo superiores, aunque se produce una considerable igualación de los mismos a partir de un determinado umbral de riqueza.

En la imputación se recurre de modo apriorístico a una estimación a partir de indicadores objetivos externos del bienestar individual y social. En estos métodos partimos de un presupuesto sobre los determinantes de la felicidad e imputamos a los individuos un determinado nivel de bienestar subjetivo en razón de variables objetivas. Nuestro método, por el contrario, es inferencial, ya que a partir de las respuestas de los individuos derivamos la construcción de una función de bienestar subjetivo.

5 Véanse al respecto Kahneman, Diener y Schwarz (1999); Frey y Stutzer (2000), Easterlin (1974 y 2001), Oswald (1997) y Putnam (2000). 
En esta línea, los estudios desarrollados por Layard (2005) ponen de manifiesto que, aunque existe un tendencia a que los países más ricos tengan índices de felicidad más altos $\left(R^{2}=0,72\right)$, es posible identificar un numeroso conjunto de países con renta per cápita más baja que se sitúan por encima de otros con rentas superiores. Asimismo, aquellos países con importantes crecimientos en su renta han experimentado mejoras en sus niveles medios de felicidad (México, India, Brasil...) pero no directamente proporcionales sino sometidos a la "ley de rendimientos decrecientes" ${ }^{6}$. En este sentido, Layard concluye que los ingresos adicionales son significativamente valiosos cuando sirven para elevar a las personas por encima del umbral de la verdadera pobreza física. Dicho de otro modo, la ley de los rendimientos marginales decrecientes se puede aplicar tanto a la renta como a todo lo que la renta puede comprar, esto es, aumentos sucesivos en los niveles de renta generan elevaciones progresivamente menores del bienestar subjetivo, hasta el punto que se podrían justificar niveles de incremento cero o negativos (desutilidad).

Otro de los resultados más destacables que arroja la evidencia empírica disponible es la existencia de un claro vínculo entre nivel de renta y bienestar subjetivo revelado dentro de cada economía y particularmente, cuando ésta es poco desarrollada. La riqueza de un país presenta una relación directa con la capacidad de satisfacción de las necesidades básicas cotidianas, por esta misma razón, el vínculo entre bienestar y renta es notablemente más claro en los países menos desarrollados que en los de mayor nivel de renta. Esta constatación sugiere que una vez alcanzada la satisfacción material básica las relaciones entre las variables mencionadas se tornan notablemente más complejas.

Ahora bien, a efectos de evitar posibles interpretaciones erróneas, es importante aclarar que en un país determinado y en un momento dado, la correlación entre nivel de ingresos y felicidad es sólida. Es decir, quienes tienen más renta se declaran porcentualmente más felices que quienes tienen menos renta. Esta relación se mantiene, aunque de forma sensiblemente más débil, cuando otros factores ligados a la renta son controlados (salud, educación...).

Realizadas las anteriores consideraciones estamos en condiciones de introducir la paradoja de Easterlin, cuya formulación es bastante simple: en las sociedades desarrolladas las elevaciones de los niveles de renta no generan un incremento en los niveles generales de bienestar de los individuos ni del colectivo, aunque existe una relación directa entre niveles de bienestar individual e ingreso personal.

Para explicar esta aparente paradoja se han avanzado una serie de hipótesis que atacan, desde la heterodoxia más próxima a la socioeconomía, las limitaciones consustanciales al enfoque predominante (mainstream) de la ciencia económica. Este último se concentra en las variables de tipo material (ingreso, consumo,

A título de ejemplo, se observa que a partir de los 20.000 dólares per cápita los incrementos sucesivos de renta no implican incrementos significativos en los niveles de felicidad.

FELICIDAD, BIENESTAR SUBJETIVO... 307 
riqueza) y abandona, por su difícil formalización o no ser directamente controlables, las de tipo social (aspiraciones, libertad, capital social, salud...). A continuación se sintetizan aquellas propuestas que consideramos más destacables.

Inglehart (1996), por ejemplo, ha avanzado como explicación la hipótesis de que las sociedades que presentan esta paradoja están en una fase de transición entre dos visiones del mundo: la materialista y la posmaterialista. Detrás de esta sustitución en los sistemas de valores se encuentra la combinación de elevadas tasas de crecimiento económico y los notables progresos en el Estado del Bienestar. Tal y como afirma este autor, para una nueva generación el crecer con la conciencia de que la supervivencia está garantizada se traduce en una sensación de seguridad existencial que, unida a la disposición de mayores niveles de renta, constituye la variable clave a la hora de explicar la emergencia del posmaterialismo. Éste fenómeno se ha venido evidenciando en las economías desarrolladas desde los años setenta del siglo pasado, cuando se incorporaron a la edad adulta las primeras generaciones que vivieron estos nuevos contextos. Para este grupo social las mejoras económicas adicionales no generan incrementos significativos en el bienestar si este aumento conlleva caídas en los componentes no-materiales de la calidad de vida.

En una línea similar, Hirschman (1982) sugiere la idea de la existencia de un ciclo generacional de carácter pendular. La generación siguiente asume como naturales los niveles de bienestar y logros materiales de la precedente, por consiguiente, las aspiraciones surgen en otros ámbitos (por ejemplo, lo político o lo social). No obstante, los progresos en estas áreas tropiezan con el mismo problema de rendimientos decrecientes, de forma que las generaciones futuras pueden retornar sobre objetivos de corte materialista, abandonando pretensiones políticas o sociales.

En conjunto, al margen de las dificultades de contrastación de las citadas hipótesis, lo que puede afirmarse es la decreciente capacidad de la renta en términos agregados para proporcionar mayores cotas de bienestar. Además, por encima de los niveles de pobreza, las diferencias de bienestar dentro de un país presentan una relación más tenue con los niveles de renta de lo que cabría esperar. De hecho, los más ricos solo manifiestan una ligera mayor propensión a considerarse felices.

Esta constatación es coherente con la máxima de que la felicidad parece guardar más relación con desear lo que se tiene que con obtener lo que se desea. Para explicar este resultado la literatura sobre el posmaterialismo habla de la "noria hedónica" (hedonic treadmill) o el binomio logros-aspiraciones. Esto significa básicamente que a medida que aumentan los logros del individuo también lo hacen sus aspiraciones, con lo cual el nivel de satisfacción se mantendría inalterado. En otras palabras, una parte de la población podría optar por incrementar su renta como medio para incrementar su nivel de bienestar subjetivo, sin tener en cuenta 
los costes derivados en otras dimensiones. De modo semejante, si se adopta la perspectiva del bienestar psicológico, los datos vienen a confirmar que cuanta más importancia se le confiere a los objetivos materiales o financieros menor es el bienestar subjetivo, mientras que, por el contrario, el progreso en el logro de objetivos de índole más intrínseca lo aumenta (Ryan y Deci, 2001).

La teoría de la renta relativa desarrollada por Duesenberry (1949) afirma que la satisfacción que una persona obtiene de sus ingresos no depende del nivel absoluto de los mismos, sino de su nivel relativo. De este modo, la satisfacción o bienestar subjetivo de una persona estaría positivamente relacionada con su nivel de ingresos y negativamente con los ingresos de los demás. Por lo tanto, en un contexto extremo en el que solo importen los ingresos relativos, los efectos de una elevación de la renta personal podrían verse disminuidos e incluso eliminados, si estos fuesen asociados a una elevación general del nivel de renta. Concretamente, los resultados aportados por Layard (2005) ponen de manifiesto que si los ingresos generales se incrementan a la par, nuestra felicidad ascendería, pero solo dos tercios de lo que lo hubiese hecho si solo se incrementase nuestra renta (Layard, 2005). Si ligamos esta explicación con la noria hedónica, nuestra felicidad dependerá fundamentalmente de nuestros ingresos en relación a nuestras aspiraciones y éstas, a su vez, dependen de los ingresos medios de las personas de nuestro entorno. No obstante, conviene aclarar que este efecto no solo es generado por las comparaciones de sesgo envidioso, sino también por la pugna por el logro de bienes posicionales, es decir, bienes de lujo con oferta inelástica en el largo plazo y elevada elasticidad renta (automóviles de lujo, obras de arte...). Estos bienes escasos, cuya posesión marca las jerarquías sociales, ven incrementada su demanda exponencialmente cuando se incrementa el crecimiento económico.

Un último tipo de explicación a la paradoja de Easterlin tiene que ver con las características de los bienes consumidos. Es preciso distinguir entre bienes defensivos y bienes creativos. Los primeros son productos destinados a impedir o remediar daños y, los segundos, productos destinados a generar una satisfacción. Aunque esta división puede resultar un tanto ambigua, sin embargo, puede afirmarse que conforme crece el PIB, crece la carga de bienes defensivos como consecuencia del crecimiento del ámbito del mercado en la vida social.

Teniendo en cuenta todo lo anterior, podríamos afirmar que cada individuo tiene unas características más o menos innatas y que en función de las mismas alcanza un determinado nivel de felicidad que experimenta leves variaciones a lo largo de toda su vida. Cuando el nivel de renta aumenta se produce un incremento de bienestar subjetivo durante algún tiempo para, una vez adaptados a la nueva situación, retornar al nivel de satisfacción de referencia. Así, tal y como señala Easterlin, aunque en el corto plazo los que poseen más ingresos son más felices, si consideramos el ciclo vital en su conjunto, la felicidad media de un 
grupo permanece constante, aunque exista un incremento notable en su nivel de ingresos (Easterlin, 2001). Los individuos una vez alcanzados sus objetivos, modifican al alza sus aspiraciones para retornar nuevamente a las posiciones de partida en cuanto a nivel de satisfacción. Layard (2005), llega a concretar que el grado de adaptación puede llegar a alcanzar el 40\% del incremento de satisfacción generado por una elevación de la renta. Consecuentemente, el ingreso al que se aspira, el que podría ser considerado como suficiente para satisfacer las necesidades de la familia, es endógeno al ingreso del que se disfruta y se incrementa conforme éste aumenta. De este modo, la brecha aspiracional no se reduce conforme el ingreso se eleva. Así, es posible encontrar personas con elevados niveles de ingreso con una brecha aspiracional porcentualmente mayor que individuos de bajos ingresos (Stutzer, 2004).

En síntesis, los individuos dedican demasiados recursos a aumentar los ingresos porque creen que así mejorará su nivel de vida y de satisfacción personal, resultando que dichos recursos se utilizan ineficientemente, no solo porque se da una adaptación a la nueva situación, sino que además existen efectos colaterales negativos. Los individuos no dejan de percibir que, a causa de la adaptación hedónica y de la pugna social, las aspiraciones se modifican en función de las circunstancias efectivas. Por consiguiente, se dedica una cantidad de tiempo desproporcionada a la obtención de objetivos monetarios, a expensas de la vida familiar y la salud, disminuyendo el bienestar subjetivo respecto al nivel esperado. Un cambio de asignación del tiempo que diera preeminencia a la vida familiar y a la salud aumentaría el bienestar subjetivo.

De lo señalado anteriormente resulta en extremo difícil ofrecer un modelo integrador que permita dar cuenta de la variada casuística existente. Ryan y Deci (2001) concluyen que lo único que es posible afirmar es que evitar la pobreza, vivir en un país desarrollado y tener objetivos vitales no directamente relacionados con logros materiales está directamente asociado a mayores niveles de felicidad y que, a partir de un cierto umbral, los incrementos de renta tienen escasa traducción en los niveles de bienestar subjetivo revelado.

\subsection{UNA PERSPECTIVA HOLÍSTICA: RETORNANDO A ARISTÓTELES}

La práctica totalidad del pensamiento filosófico clásico premoderno desde Aristóteles sostuvo el carácter de la felicidad, entendida como "vida buena", como fin último de la acción humana. Ahora bien, la felicidad no era concebida como una realidad estática, sino como una actividad (Ética a Nicómaco, 9) o, tal y como lo interpreta MacIntyre (1988), como la condición del estar bien y del hacer estando bien. Es claro que esta definición tiene un evidente componente ético y no puede identificarse con el reduccionismo hedonista. 
Para esta aproximación clásica la felicidad presenta al menos dos rasgos paradójicos: la socialidad y la calidad de la felicidad.

Desde la perspectiva aristotélica el hombre es esencialmente un ser social, con lo que la felicidad tiene una dimensión relacional, es decir, depende también de relaciones sociales, lo que denominaremos bienes relacionales (Nussbaum, 1993). Consecuentemente, este objetivo vital (la felicidad) no puede lograrse de modo instrumental, sino que surge como resultado indirecto de acciones que se apartan de la necesidad estricta. Es decir, aunque el objetivo esencial de ser feliz es de carácter individual, el logro del mismo no es resultado exclusivo de una actividad del individuo orientada a tal efecto. Este problema podría ser enunciado como la fragilidad de la eudemonía ${ }^{7}$, puesto que depende de los otros (bienes relacionales) y de la libertad.

Además, nos enfrentamos al problema de la calidad de la felicidad. Tal y como planteaba Stuart Mill (1851), la felicidad guarda relación con el desarrollo cultural y, en particular, con el capital humano, con lo que puede variar tanto en cantidad como en calidad en función del tipo de experiencia individual. En la medida en que calidad y cantidad de felicidad no son perfectamente sustituibles, ambas han de tenerse en consideración. De hecho, menor cantidad de una clase más elevada es preferible a una mayor cantidad de una clase más baja y la determinación del grado de calidad queda establecida por la preferencia de quienes tienen conocimiento de ambas. Recogiendo el ejemplo de Mill, Sócrates preferiría ser un Sócrates insatisfecho a un cerdo satisfecho; el cerdo probablemente no; pero el cerdo solo conoce un lado de la cuestión, y Sócrates conoce ambos.

La idea de felicidad que está proponiendo Stuart Mill pasa a formar parte de toda la tradición clásica en el ámbito de la economía hasta Keynes y podría quedar recogida en la siguiente afirmación: la felicidad depende de un complejo conjunto de variables extraeconómicas que van desde la religión y el problema del sentido de la vida hasta las relaciones personales, por tanto, es un fenómeno de naturaleza social. No obstante, aunque la extrema pobreza no significa automáticamente la infelicidad, dificulta de hecho las condiciones objetivas que hacen posible desarrollar aquellas dimensiones vitales de las que depende. Este supuesto elemental y la orientación cuantitativista de la Economía dieron lugar a una limitación del enfoque a las cuestiones materiales marginando otras más difícilmente cuantificables que ya hemos mencionado.

Frente a este reduccionismo, la perspectiva de las capabilities de Sen opta por distinguir en el más puro sentido aristotélico entre felicidad, como equivalente a satisfacción material, y eudamonía como cumplimiento de la naturaleza

El término eudemonía es central en la ética aristotélica al plantear que el único objetivo de la vida humana es el logro de una "vida buena". 
humana (human flourishing) (Nussbaum y Sen, 1993 y 1999). A partir de este planteamiento, este autor cuestiona el verdadero contenido informativo de los indicadores económicos tradicionales como reveladores del nivel de vida. Consecuentemente, la concepción del desarrollo evoluciona desde una identificación del mismo con los ingresos hacia una visión que lo asocia más bien a la ampliación de capacidades o posibilidades en manos de los ciudadanos, lo cual puede ser interpretable incluso en términos de libertades. Así, el desarrollo humano posee una doble dimensión ${ }^{8}$ : en primer lugar, la formación de las capacidades humanas (renta, salud y conocimientos) y, por otra parte, el uso que la población hace de esas capacidades adquiridas (descanso, producciones y actividades culturales, sociales y políticas). Por lo tanto, el análisis del desarrollo a través de la renta es una posible vía de aproximación pero no excluyente. En una línea similar, Rawls (1971) analiza y define los bienes primarios como aquellos que precisan los individuos cualesquiera que sean sus fines. Concretamente, se trata de medios de uso general que ayudan a todos los miembros a promover sus objetivos vitales y comprenden las libertades, las oportunidades, la renta y las bases sociales del respeto a uno mismo.

En general, los trabajos de estos autores son pioneros en el reenfoque de este problema reclamando el carácter eudemonista de cualquier ciencia humana o social. Este tipo de estudios divergentes de la metodología económica más convencional permite adoptar un nuevo enfoque sobre problemas esencialmente económicos que precisan una aproximación más holística. En concreto, esta revisión es trascendental desde el punto de vista de la política económica, en la medida en que un replanteamiento de los objetivos últimos de toda actuación pública puede suponer alterar tanto la dirección de los instrumentos manejados como los propios instrumentos.

\subsection{UNA APROXIMACIÓN EMPÍRICA A LA FUNCIÓN DE FELICIDAD DE LOS GALLEGOS}

En el marco de esta línea revisionista de los vínculos entre renta, ingreso o crecimiento económico con desarrollo o bienestar, el estudio de bienestar subjetivo declarado resulta especialmente significativo, en orden a identificar una función microeconométrica de bienestar o felicidad, en la que se incorporen determinantes de muy diverso carácter: sociales, individuales, económicos, políticos, etc.

Como ya hemos señalado, parece obvio afirmar que la naturaleza última del ser humano es su carácter social o relacional y en consecuencia, que nuestra felicidad o infelicidad va a depender en buena medida de la cantidad y calidad

8 Realmente, Sen participa de una amplia tradición de pensamiento que puede remontarse hasta Aristóteles y en la que la prosperidad se identifica con capacidades y posibilidades más que con la renta. La vertiente más reciente de esta tradición es el Programa de las Naciones Unidas para el Desarrollo, (PNUD) en sus informes desde 1990. 
de las relaciones establecidas con los otros. Es precisamente en este punto, donde se hacen más evidentes las limitaciones del enfoque tradicional de la ciencia económica centrado en la existencia de un agente individual separado (in-dividuum) y que considera la dimensión relacional de la existencia humana como algo extrínseco, accidental o instrumental (Peiro, 2004). Junto a este factor clave, la literatura teórica sobre el tema (Frey y Stutzer, 2002; Layard, 2003 y 2005; Veenhoven, 1993; 2000 y 2001; Easterlin, 1974; Frey y Stutzer, 2000) ha identificado los siguientes determinantes socioeconómicos de la felicidad de los individuos:

- La salud individual y del entorno familiar presenta una fuerte relación bidireccional.

- La existencia de una red de relaciones sociales o el capital social y los bienes relacionales. En concreto el estado civil parece guardar una relación fuertemente directa con el nivel de bienestar.

- La situación laboral, esto es, la incorporación o no al mercado de trabajo ha resultado determinante, tanto por su capacidad de generación de ingresos como por el desarrollo de las capacidades creativas y sociales.

- La edad. La felicidad no es constante a lo largo de la vida, la interrelación con otras variables como la salud y los ingresos apunta a un decrecimiento de la felicidad con la edad.

- La estabilidad y desarrollo político de la sociedad pueden influir de forma decisiva en la generación de redes de participación y confianza ciudadana.

- Los valores. Detrás del problema de la felicidad se encuentra también un cierto problema de cultura vital o de primacía de un determinado tipo de valores.

- La renta y su distribución. El nivel de renta está asociado positivamente con el grado de felicidad, en tanto que la desigualdad económica lo está negativamente.

Un primer análisis de las correlaciones de Spearman sobre los resultados de la Encuesta Mundial de Valores realizada para Galicia (Tabla 10.1) nos permite establecer unas relaciones básicas que serán de gran utilidad para nuestro análisis posterior. Al mismo tiempo, estas correlaciones nos anticipan las interrelaciones existentes entre los diversos determinantes. 


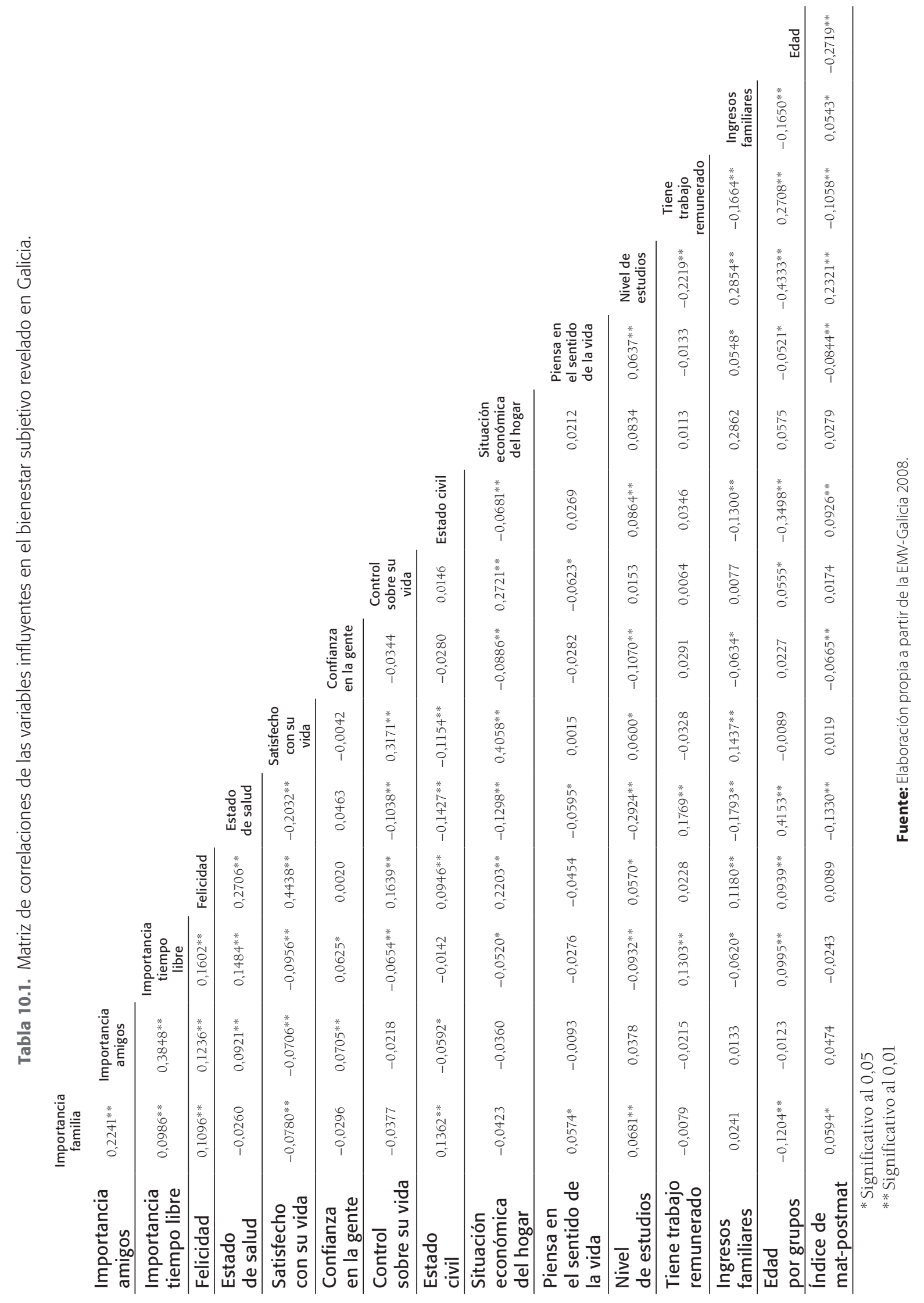


Una primera asociación evidente que se desprende de la tabla de correlaciones es el vínculo existente entre la felicidad y la salud individual. A su vez, también se observa una relación fuertemente significativa entre felicidad y la dotación de una red de relaciones sociales, esto es, el capital social. Ahora bien, es preciso realizar una importante puntualización. Los lazos sociales relevantes parecen ser solo los que podríamos denominar de bonding y bridging, es decir, los lazos familiares y la red de amistad o reciprocidad, no la sociabilidad general. Así, la relación entre felicidad y confianza generalizada es prácticamente irrelevante o no significativa.

Por otra parte, merece ser destacada la robustez de la influencia de la variable "estado civil". En particular, aquellos individuos que presentan una mayor estabilidad en sus vínculos (casados o en pareja) tienden a mostrarse notablemente más felices que los restantes.

Como es lógico, los ingresos familiares y la situación económica del hogar guardan relación directa con los niveles de felicidad expresados. Sin embargo, conviene anticipar que esta relación debe ser analizada pormenorizadamente.

En lo que respecta a la incorporación o no al mercado de trabajo, aunque a primera vista parece no tener una importancia decisiva, dada la variedad de posibles situaciones (inactivos, activos, ocupados, en formación...), el análisis que realizaremos posteriormente revela la existencia de importante vínculo entre la felicidad y esta variable.

Los perfiles valorativos (sistema de valores) de los individuos son otro de los factores que condicionan significativamente su bienestar subjetivo. En particular, el reconocimiento de la importancia de la familia y los amigos, así como del tiempo libre, parece incuestionable. No obstante, contrariamente a lo planteado por Inglehart (1996), la presencia de rasgos posmaterialistas resulta claramente no significativa.

Finalmente, la edad aparece inversamente relacionada con la felicidad, si bien es cierto que este vínculo está condicionado por la evidencia de que la evolución de la salud y los ingresos están estrechamente asociadas a esta variable.

En otro orden de cosas, puede observarse una práctica identidad entre los conceptos "felicidad" "satisfacción vital" y "libertad y control sobre su vida". En tanto que resulta obvia la relación entre las dos primeras, la identidad con la tercera ya había sido resaltada por el enfoque humanista. La felicidad puede ser entendida como un progreso en el proceso de humanización y se traduce por una mayor libertad y realización personal percibida por parte de los individuos.

Llegados a este punto del análisis, y a efectos de la construcción de una función de felicidad de los gallegos, se procede a la estimación econométrica de la siguiente función:

Felicidad $=\alpha+\beta_{1}$ satisfacción económica $+\beta_{2}$ situación familiar $+\beta_{3}$ salud $+\beta_{4}$ valoración de redes personales $+\beta_{5}$ valoración tiempo libre 
La estimación realizada mediante un análisis de regresión Logit nos permitirá determinar cuales son las variables explicativas a la hora de que los individuos se manifiesten como felices. En un primer modelo (Tabla 10.2) optamos por considerar exclusivamente las variables significativas relativas al grupo de aquellos que se autodefinen como muy felices frente a los restantes grupos (en el caso gallego en torno al 28\% de los entrevistados). Los resultados tienen una más que aceptable capacidad explicativa $\left(0,4\right.$ pseudoR ${ }^{2}$ de Nagelkerke) y los coeficientes estimados son altamente significativos. Concretamente, los resultados de la estimación sugieren claramente que existen tres bloques de factores que están influyendo de forma decisiva: salud, entramado social de referencia y percepción de su situación económica.

En lo que se refiere a la valoración del propio estado de salud, aunque es evidente que existe una influencia bidireccional entre ambas variables, aquellos individuos que tienen una valoración positiva sobre su estado de salud tienden a manifestarse como más felices. En segundo lugar, nos encontramos con un conjunto de tres variables claramente axiológicas o valorativas y vinculadas con la red de relaciones sociales de la que disponen los individuos. Aquellos sujetos que le conceden una mayor importancia a la familia y a la red social de pertenencia y que consideran esencial la disposición de un tiempo libre para su desarrollo personal se manifiestan considerablemente más felices. En este mismo sentido la estabilidad de la situación familiar (casados y parejas estables) ejerce una influencia significativa. Finalmente, el nivel de ingresos, tal y como hemos señalado, guarda una relación directa, ahora bien, la variable más explicativa en esta dimensión no es el ingreso en cuanto tal, sino la valoración subjetiva del nivel de renta. Esta variable guarda una relación con el nivel de ingresos, pero toma en consideración también las aspiraciones y acomodación a los mismos.

Tabla 10.2. Determinantes de los que se declaran muy felices en Galicia.

\begin{tabular}{ccc} 
Variables en la ecuación & Coef. & Sig. \\
Estado de salud & 1,158 & 0,000 \\
\hline Importancia de la familia & 0,885 & 0,034 \\
\hline Importancia de las redes de amigos & 0,489 & 0,050 \\
\hline Importancia del tiempo libre & 0,882 & 0,000 \\
\hline $\begin{array}{c}\text { Satisfacción con la situación económica } \\
\text { del hogar }\end{array}$ & 0,418 & 0,000 \\
\hline Situación familiar & 1,055 & 0,004 \\
\hline Constante & 1,922 & 0,077 \\
\hline
\end{tabular}

Fuente: Elaboración propia a partir de la EMV 2008. 
En el segundo modelo desarrollado (Tabla 10.3), el análisis de regresión se realiza sobre los factores que influyen en que los individuos se sitúen en el grupo de los que se afirman como muy felices, así como bastante felices. En este caso, se trata de un grupo más amplio que el que nos sirvió de referencia para la estimación del primer modelo. Por exclusión, en este modelo estamos analizando igualmente las variables más influyentes en aquellos que se autodefinen como no felices o poco felices.

Nuevamente, resultan decisivas las variables axiológicas entre las que destacan el reconocimiento de la importancia de la familia, las redes relacionales y el tiempo libre. Paralelamente, la salud sigue siendo una variable con una elevada capacidad discriminante, sin embargo, la renta y situación familiar pasan a un segundo plano. En este caso presentan un mayor poder explicativo el nivel de estudios y el tamaño del municipio de residencia. En lo que respecta al primero, éste guarda una elevada relación con el nivel de ingresos pero al mismo tiempo está más ligado al nivel de desarrollo humano general. Finalmente, el tamaño del municipio está directamente vinculado a la centralidad municipal y al acceso a los bienes y servicios urbanos (educación, salud...).

Si realizamos una lectura a la inversa, aquellos que se manifiestan como menos felices en Galicia son aquellos con entornos familiares menos estables, peores condiciones de salud, bajos niveles educativos y residentes en municipios de escasa dimensión.

Tabla 10.3. Determinantes de los que se declaran felices en Galicia.

\begin{tabular}{ccc} 
Variables en la ecuación & Coef. & Sig. \\
Importancia de la familia & 0,861 & 0,001 \\
\hline Importancia de las redes de amigos & 0,536 & 0,024 \\
\hline Importancia del tiempo libre & 0,531 & 0,006 \\
\hline Estado de Salud & 1,109 & 0,000 \\
\hline $\begin{array}{c}\text { Tamaño del municipio } \\
\text { de pertenencia }\end{array}$ & 0,336 & 0,013 \\
\hline Nivel de estudios & 0,347 & 0,003 \\
\hline Constante & 3,406 & 0,000 \\
\hline
\end{tabular}

Fuente: Elaboración propia a partir de la EMV-Galicia 2008.

Los resultados de las estimaciones econométricas también son interpretables en términos de dominios de vida. La satisfacción vital depende de la satisfacción en ámbitos concretos de la propia vida: dominio laboral, dominio económico, 
dominio familiar, dominio de tiempo libre. Algunos estudios previos (Rojas, 2007) han puesto de manifiesto que el dominio con mayor peso en la satisfacción vital es el de la familia, y le siguen en importancia el de la salud y el tiempo libre. De menor importancia, aunque estadísticamente significativos, son el dominio laboral y económico. Este último dominio muestra una clara relación con la satisfacción económica, pero menos influencia con la satisfacción vital. Los dos primeros, en cambio, están vinculados con los bienes relacionales, esto es, aquellas acciones desinteresadas de las relaciones humanas y guiadas por motivaciones intrínsecas que producen bienestar al generar experiencias afectivas positivas. Estos bienes tienen la particularidad de no guardar relación con el ingreso y ser tiempo-intensivos, con lo cual contribuyen a explicar que la relación entre ingresos y felicidad no sea tan directa.

En definitiva, la evidencia obtenida para el ámbito gallego viene a corroborar la obtenida en otros estudios realizados a nivel general (Layard, 2005), los factores determinantes de la felicidad más destacables son: la situación financiera y trabajo, las relaciones sociales con nuestra comunidad de referencia, nuestra salud y libertad personal y nuestros valores personales (Figura 10.1). De este modo, la "función de felicidad" derivada de los resultados de la muestra se aproxima a tendencias observadas en otras sociedades desarrolladas, pero refleja también particularidades del entorno gallego. Concretamente, la presencia de variables como el tamaño municipal trasluce las desigualdades de desarrollo socioeconómico y las singularidades de la demografía, es decir, la diversidad de entornos que caracterizan la sociedad gallega.

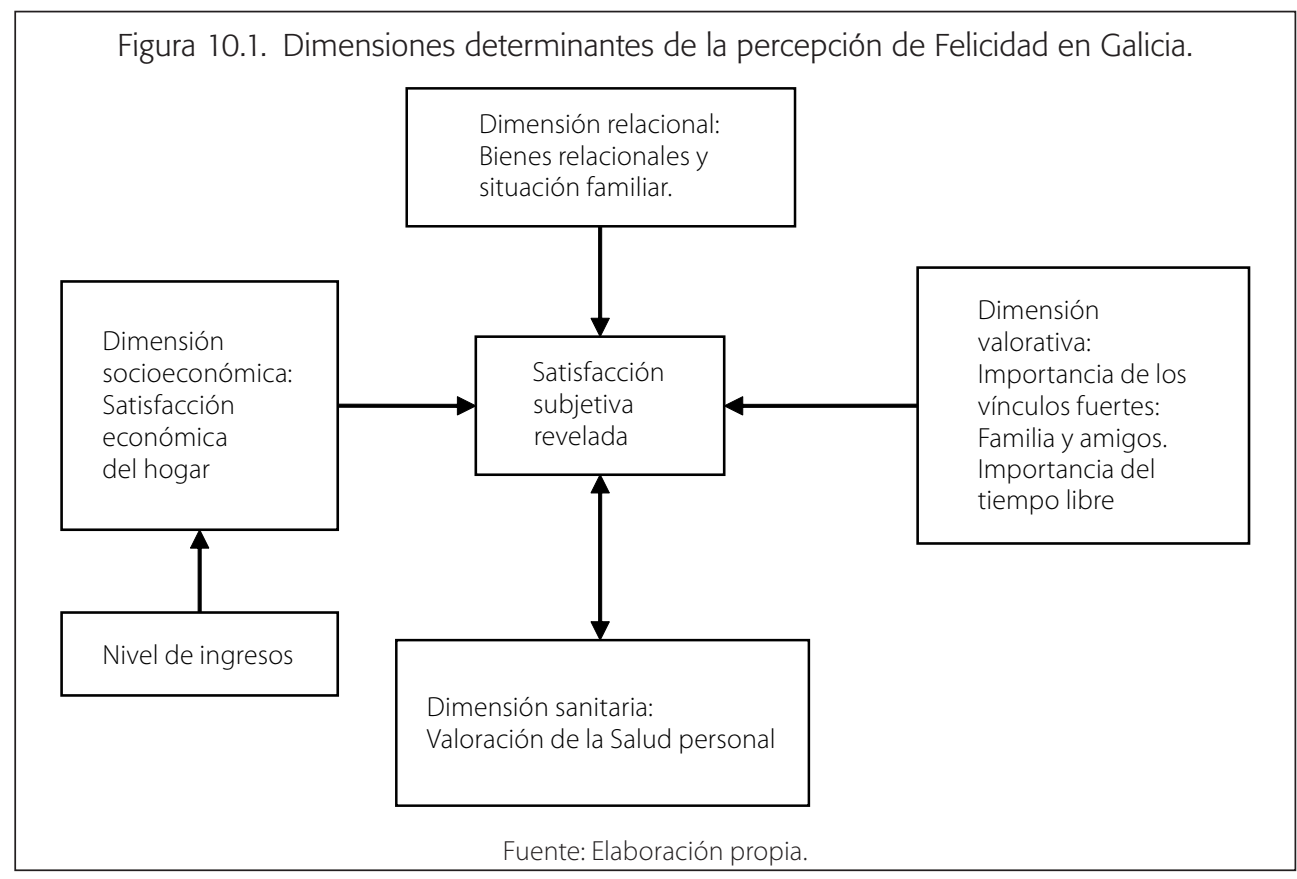




\subsection{TRAYECTORIA DE LA FELICIDAD Y SUS DETERMINANTES EN GALICIA}

La discusión de los resultados que se desprenden del anterior estudio econométrico puede completarse con el análisis descriptivo de la evolución, tanto de la variable dependiente en la ecuación de felicidad como de las variables explicativas de la misma.

\subsubsection{Percepción de la felicidad}

A primera vista, un simple seguimiento de la evolución de la percepción de la felicidad en Galicia (Gráfico 10.1) nos permite constatar dos hechos, por un lado, un muy elevado porcentaje de los gallegos se declara bastante o muy feliz (un porcentaje próximo al 90\%) y, por otro, la mejora experimentada en el período objeto de estudio (1995-2008). Dicha mejora se refleja tanto en la reducción del porcentaje de los que se declaran poco o nada felices (que pasan de cifras cercanas al 14\% a algo inferiores a un 10\%), como en el significativo incremento de aquellos que se declaran muy felices (pasan de un 16,4\% en el año 1995 a un 28,11\% en el 2008).

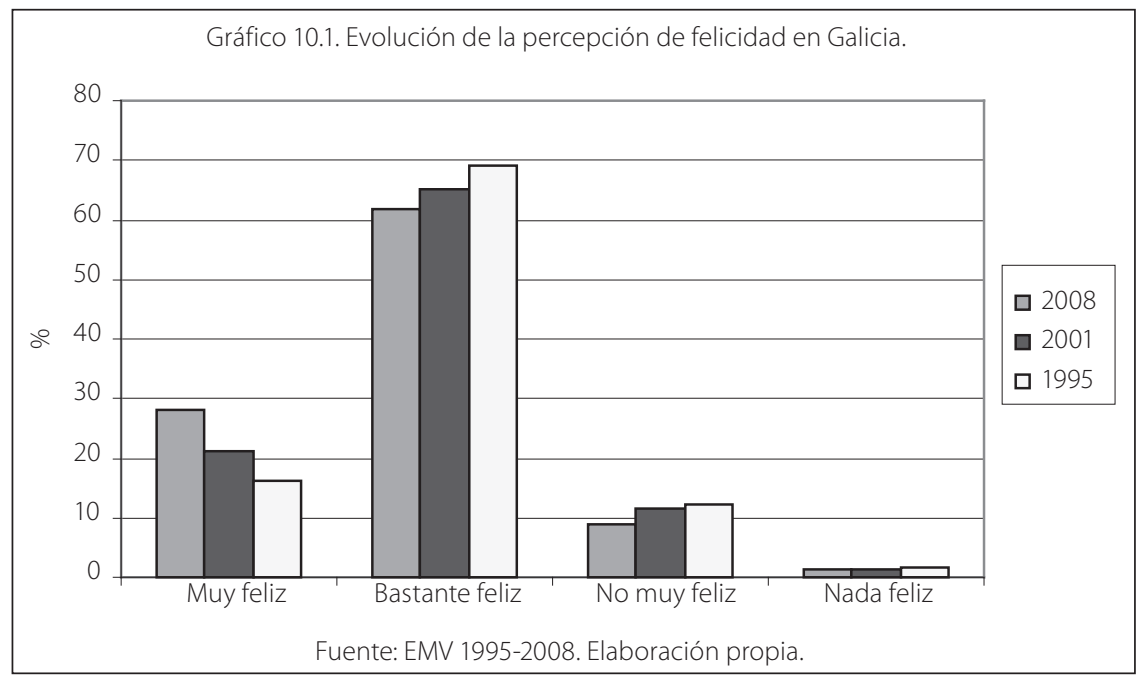

Esta evolución adquiere especial significación en la medida en que supone un notable distanciamiento del contexto general de la sociedad española (Gráfico 10.2). En efecto, para el conjunto de España se verifica una reducción del porcentaje de la población que manifiesta decididamente una elevada satisfacción subjetiva hasta situarse en el 13,6\% (frente al 28\% de los gallegos).

En términos generales se podría hablar de la aparición de una clase de satisfechos en la sociedad gallega que se aproxima a un tercio de la población. Junto a esto, es 
reseñable la ruptura de una tendencia conjunta que caracterizaba a las realidades gallega y española en la evolución de esta variable en el período que va desde el 2000 al 2008. Las causas son notablemente difíciles de determinar y podrían ser tanto de naturaleza económica (evolución de la renta, evolución de las coberturas sociales...) como sociales (particularidades de la sociedad gallega frente a la española...) y políticas. Estos factores no son escindibles los unos de los otros, de forma que habría que considerar el desarrollo socioeconómico en general.

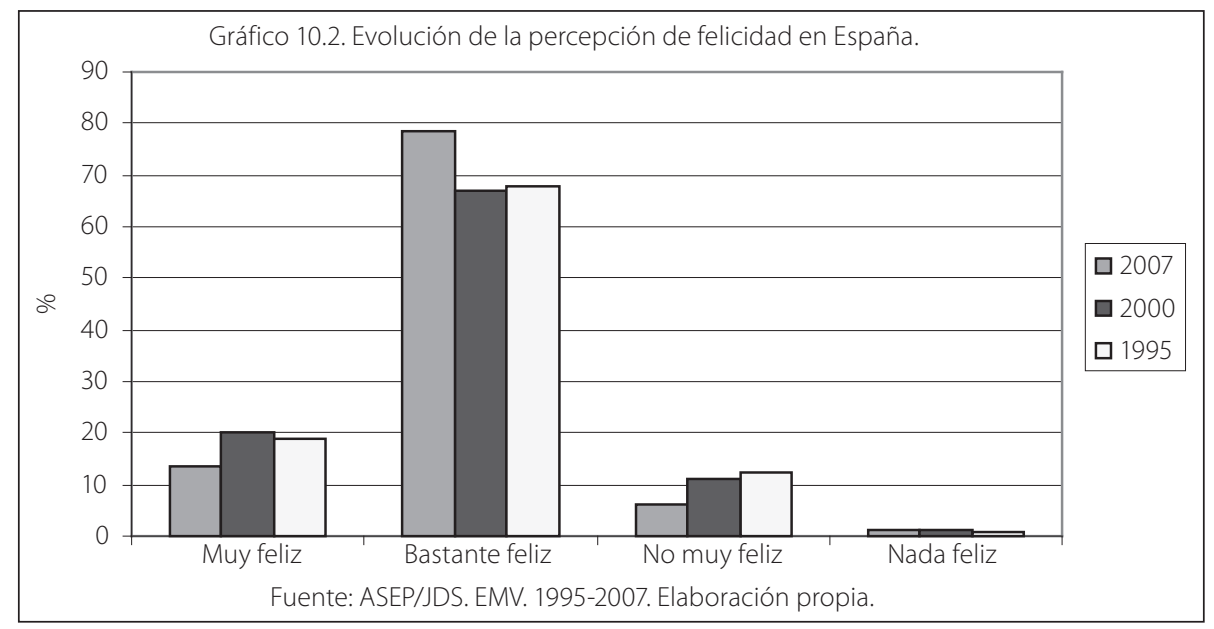

En el contexto de los países europeos para los que existen datos de la EMV, Galicia se sitúa claramente dentro de la tendencia general. Sobre el Gráfico 10.3 puede observarse la relación directa existente entre nivel de PIB, considerado en términos de paridad de poder adquisitivo, y el agregado de aquellos que se consideran muy o bastante felices. Pese a que se trata de un conjunto reducido de datos, concretamente diecinueve, podrían proponerse ya algunas lecturas ligadas a la hipótesis de Easterlin sobre la trayectoria conjunta de ambas variables. En principio una interpretación apresurada apreciaría una relación lineal, no obstante el mejor ajuste de ambas variables es una curvilínea logarítmica e incluso una función cuadrática ( $\mathrm{R}^{2}$ de 0,56 y 0,58 respectivamente). Ambas aproximaciones sugieren tanto la existencia de rendimientos decrecientes en la renta en su capacidad de "generación de felicidad" como, en el segundo de los casos, la posibilidad de incrementos sucesivos en el nivel de renta no den siempre lugar a mejoras en los niveles de satisfacción subjetiva revelada.

Nuestra aproximación a la evolución de la percepción de la felicidad puede complementarse con las respuestas de los gallegos a la pregunta sobre la satisfacción respecto a la propia vida (Gráfico 10.4). En consonancia con lo señalado anteriormente, los resultados ponen de manifiesto el crecimiento del grupo de los que pueden ser calificados como satisfechos. Pese a que en este estudio estamos considerando ambos conceptos como asimilables, conviene aclarar que algunos 
autores, generalmente provenientes del campo de la psicología, distinguen entre felicidad y satisfacción. Esta última supone un proceso cognitivo que involucra las aspiraciones del individuo, en tanto que la felicidad supone un estado afectivoemocional. Ahora bien, muchos factores asociados a la satisfacción vital son, en gran medida, semejantes a los que determinan la felicidad de forma que las trayectorias de ambas están directamente asociadas.

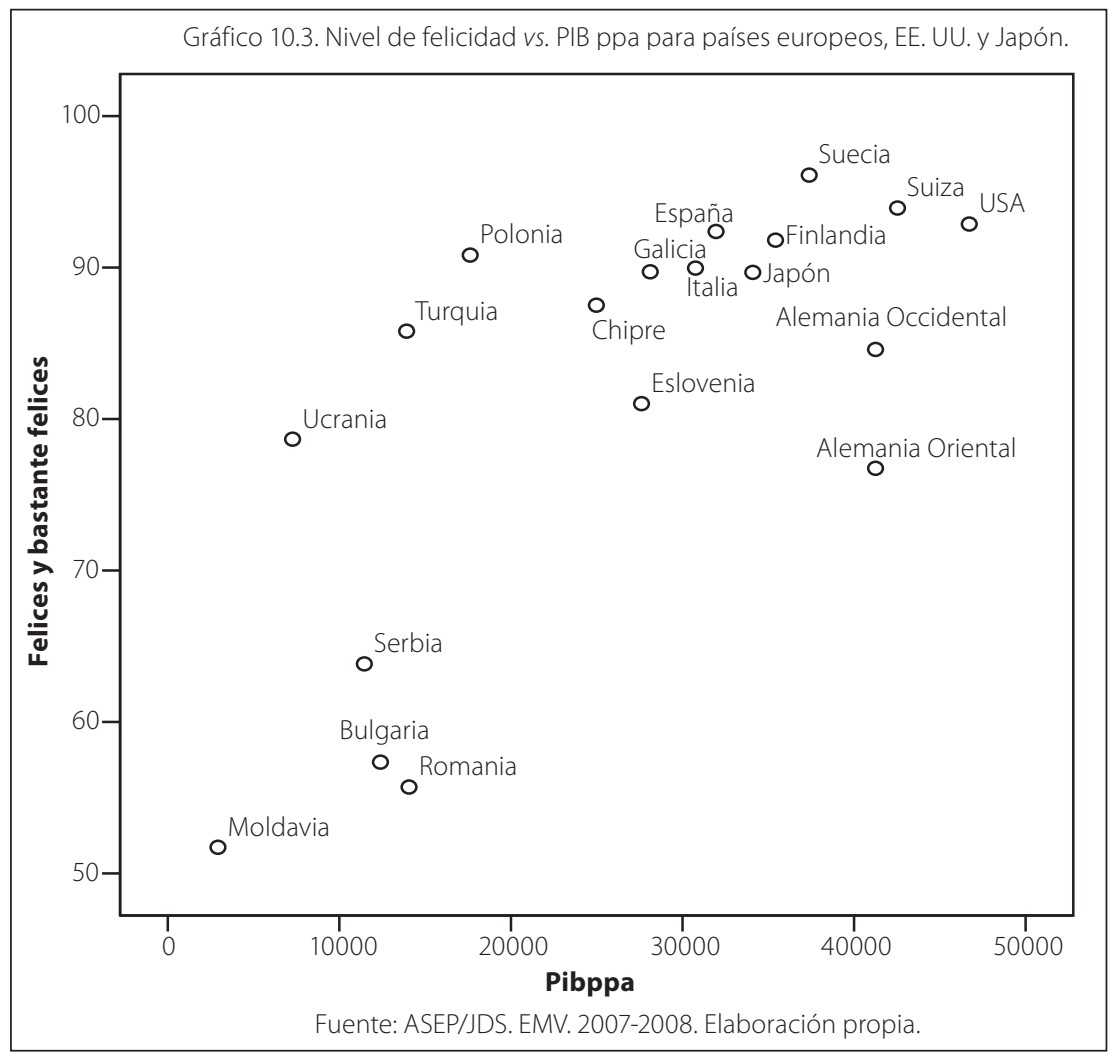




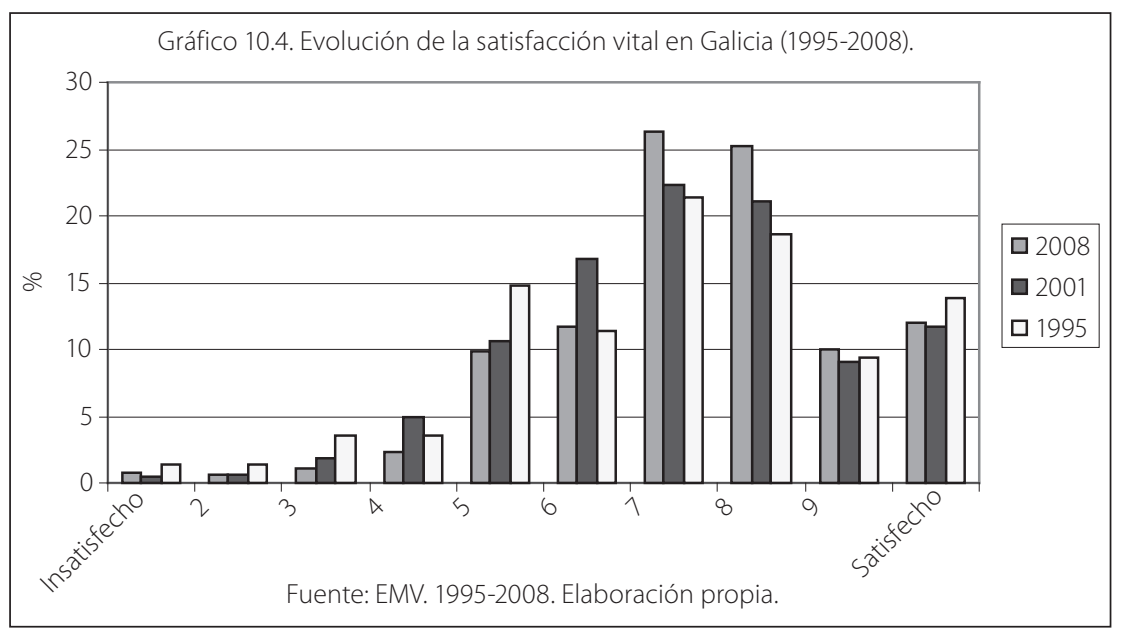

Para el conjunto de la población gallega se observa un considerable incremento de aquellos que se declaran satisfechos con su propia vida a lo largo del período. Por una parte, se reducen progresivamente los que se manifiestan como insatisfechos hasta representar un porcentaje en torno al 5\% en tramos inferiores al 5 en una escala de 10 posiciones. Por otra parte, más de un 70\% de los encuestados se sitúa en posiciones claramente identificables con una notable satisfacción vital (superiores o iguales a 7). Lo que es más, la media, mediana y moda de la muestra se sitúa entre las posiciones 7 y 8 .

En esta variable las diferencias respecto al conjunto de España (Gráfico 10.5), al igual que ocurría en el grupo de los muy felices, vuelven a evidenciar divergencias en el porcentaje de población que se integra entre los muy satisfechos. En Galicia su volumen es más del doble que el español. Concretamente, más de un $12 \%$ de la población se emplaza en el máximo nivel frente a un escaso $6 \%$ en la encuesta realizada sobre la población española. 


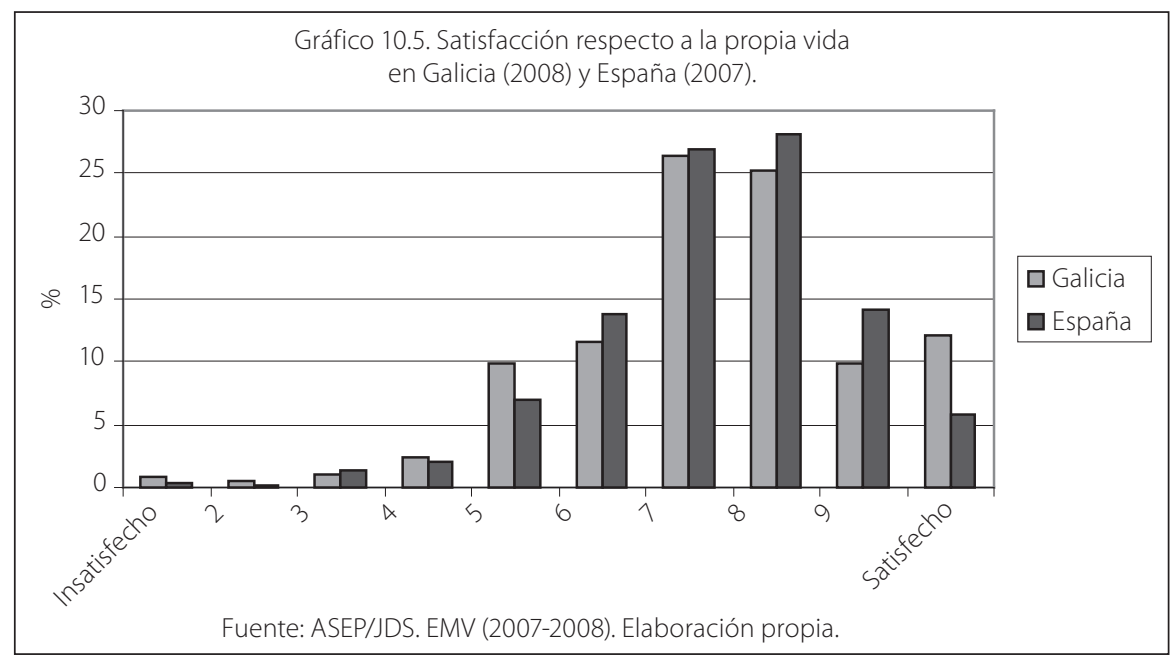

\subsubsection{Renta, desarrollo y felicidad}

Tal y como se ha mencionado anteriormente, de los datos manejados para el caso gallego en materia de percepción de la felicidad parece desprenderse un movimiento hacia una sociedad "satisfecha" en el período que va desde la primera oleada (1995) hasta la última realizada (2008) ${ }^{9}$. Esta constatación, en cierto modo, vendría a contradecir lo planteado por la paradoja de Easterlin, ya que el incremento de la renta y la mejora general de las condiciones de vida en Galicia parecen haber sido más decisivas de lo que predice la teoría.

En particular y en lo que respecta a la evolución de la renta como factor determinante de la felicidad de los gallegos, conviene tener presente que a lo largo del período analizado se ha producido una sensible convergencia que puede contribuir a explicar la relevancia de esta variable ${ }^{10}$. Galicia partía de una posición de retraso relativo en términos de renta per cápita tanto frente a la media española como a la de la Unión Europea (Gráfico 10.6). La recuperación de $10 \%$ de las diferencias desde 1995 (Galicia pasa de disponer un 82\% de la renta media a prácticamente un $88 \%$ y de un $68 \%$ a un $80 \%$, respecto al resto de la Unión Europea) puede explicar una parte de la influencia de la misma sobre la felicidad. Esta influencia sería si cabe más significativa si tenemos en cuenta, tal y como ha sido analizado con anterioridad en este trabajo, que el efecto de una

9 Es evidente que la crisis económica experimentada posteriormente a la encuesta puede suponer un replanteamiento de alguna de las afirmaciones. No obstante, este trabajo analiza la tendencia de largo plazo observada en el período 1995-2008 que tiene componentes estructurales y coyunturales que pueden confundirse en una etapa de crecimiento cuasicontinuado. Las próximas oleadas de la encuesta nos permitirán discernir que parte de este movimiento ha sido coyuntural y los efectos que la crisis ha generado sobre los niveles de satisfacción.

10 No obstante, conviene aclarar que esta convergencia ha sido de carácter pasivo, esto es, por reducción del peso demográfico relativo al mismo tiempo que se experimentaban tasas de crecimiento semejantes a las del conjunto nacional (convergencia activa) (Prada y Lago, 2009). 
mejora en los niveles de renta es particularmente evidente en el momento inicial previo al proceso de acomodación a la nueva situación.

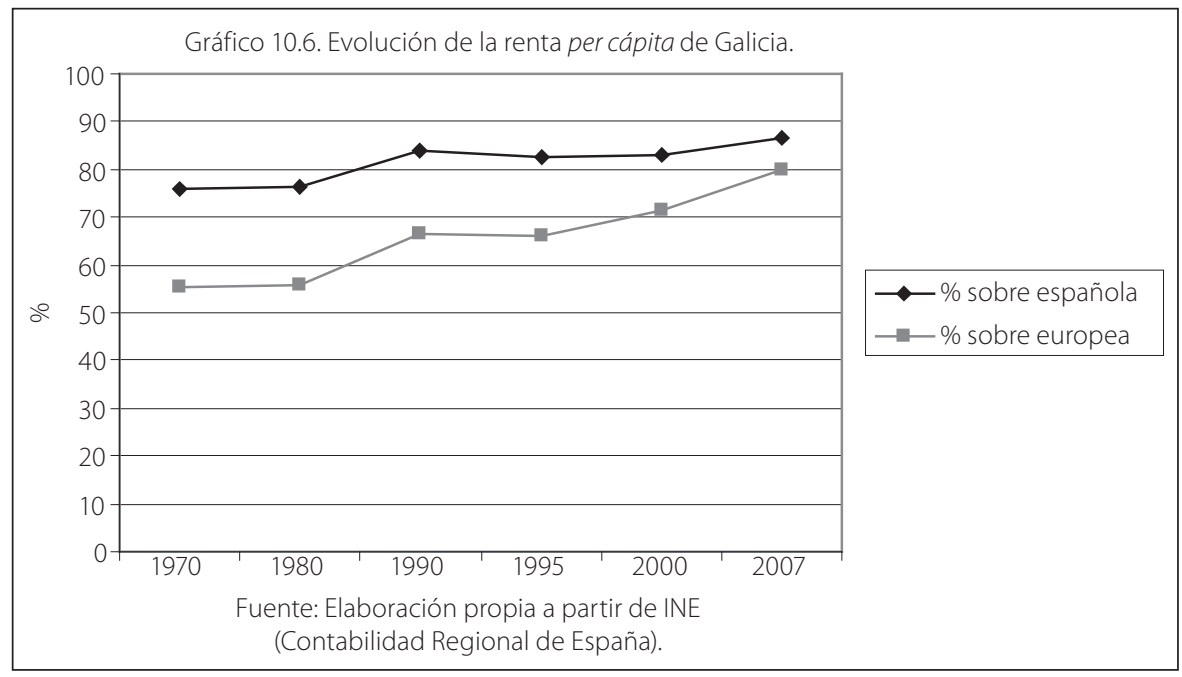

Con el objeto de evitar las visiones simplistas focalizadas en el concepto de renta monetaria, es preciso considerar el más amplio de "capacidades" o "desarrollo humano". En efecto, el incremento de la renta ha ido asociado a la mejora en las prestaciones sanitarias, las coberturas sociales, la educación, etc. que permiten generar la visión de una sociedad satisfecha. En este sentido, el Indice de Desarrollo Humano (IDH) combina de forma normalizada (valores entre 0 y 1) tres indicadores parciales: la esperanza de vida, la educación y la renta per cápita. Lógicamente, un mayor valor del índice está reflejando un mayor nivel de desarrollo de las "capabilities" o un mayor nivel de posibilidades de desarrollo personal o humanización. Junto a este indicador, también cabe considerar el Índice de Desarrollo Humano relativo al Género (IDG) que recalcula el IDH penalizando las diferencias de género y el Índice de Pobreza Humana (IPH) que refleja la probabilidad de que un individuo no supere una esperanza de vida de 60 años, el porcentaje de analfabetos funcionales y el porcentaje de individuos con ingresos por debajo de la media, así como la tasa de paro de larga duración (véase Prada y Lago, 2009).

Los datos para Galicia respecto a estos índices evidencian una importante mejora relativa en los últimos 25 años, más significativa que la convergencia en renta. Aunque Galicia figura ligeramente por debajo de la media española, se sitúa por encima de comunidades con PIB ligeramente superior (Gráfico 10.7). 


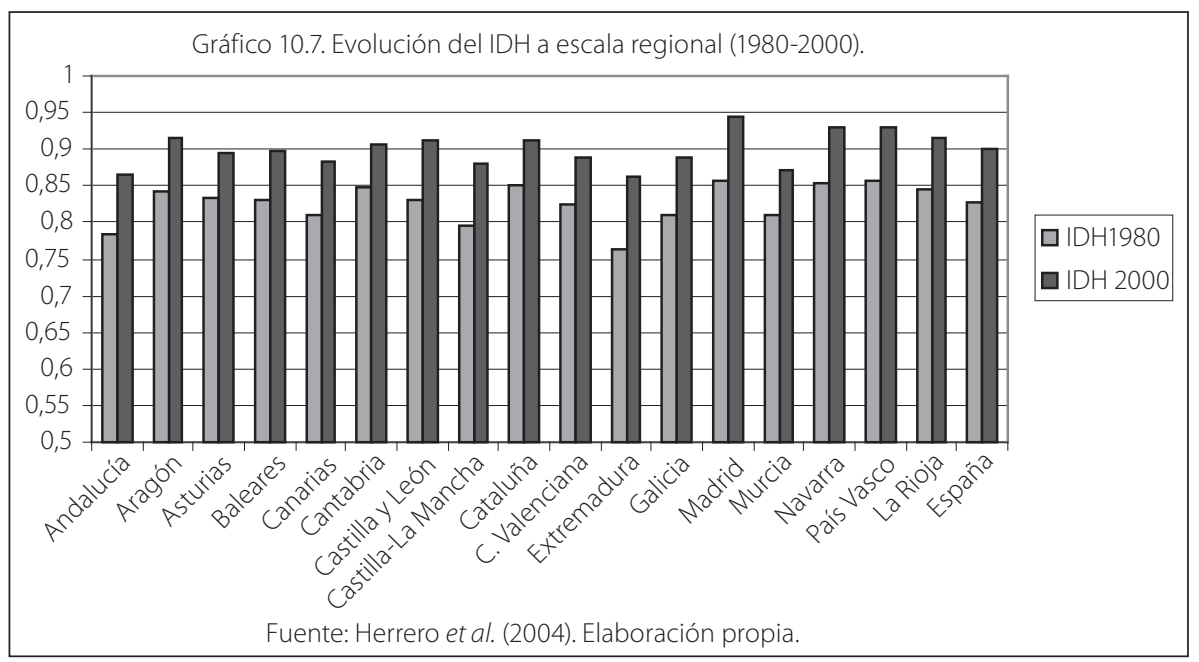

En términos de género, el IDG manifiesta una tendencia muy semejante al IDH, con lo que podría afirmarse que Galicia no es una comunidad donde la discriminación por sexos sea especialmente marcada. Finalmente, en términos de IPH Galicia se posiciona de forma similar aunque ligeramente inferior, lo cual puede verse causado por la persistencia de un pequeño porcentaje de analfabetismo.

A modo de síntesis y atendiendo la evolución de los anteriores indicadores, cabe destacar que, desde una perspectiva dinámica, Galicia ha mejorado sensiblemente su posición relativa en el concierto autonómico. Esta mejora es más ostensible si consideramos indicadores de desarrollo general y no solo de crecimiento de renta. Este período de expansión prolongada asociada a importantes transformaciones sociales y de mejora en las dotaciones de capital humano y prestaciones sanitarias, puede dar razón de estos cambios en la satisfacción subjetiva revelada. Tras esta convergencia más acusada que la derivada del crecimiento en renta relativa se encuentra la extensión del Estado de Bienestar. Así, el mayor peso de este proceso de convergencia ha recaído en el ámbito educativo. La generalización de la educación, la eliminación del analfabetismo y los avances en la educación superior han dado lugar a una importante disminución de las desigualdades en términos de capacidades. Simultáneamente, las mejoras en el sistema sanitario han generado un sensible incremento en la esperanza de vida (Gráfico 10.8). Ahora bien, es importante contextualizar estos resultados en el momento en que se realiza la encuesta, esto es, 2008 y el comienzo de una crisis económica que se agudiza en los años posteriores. Esta nueva coyuntura puede suponer importantes alteraciones tanto en la percepción de los niveles de felicidad como en sus determinantes. 


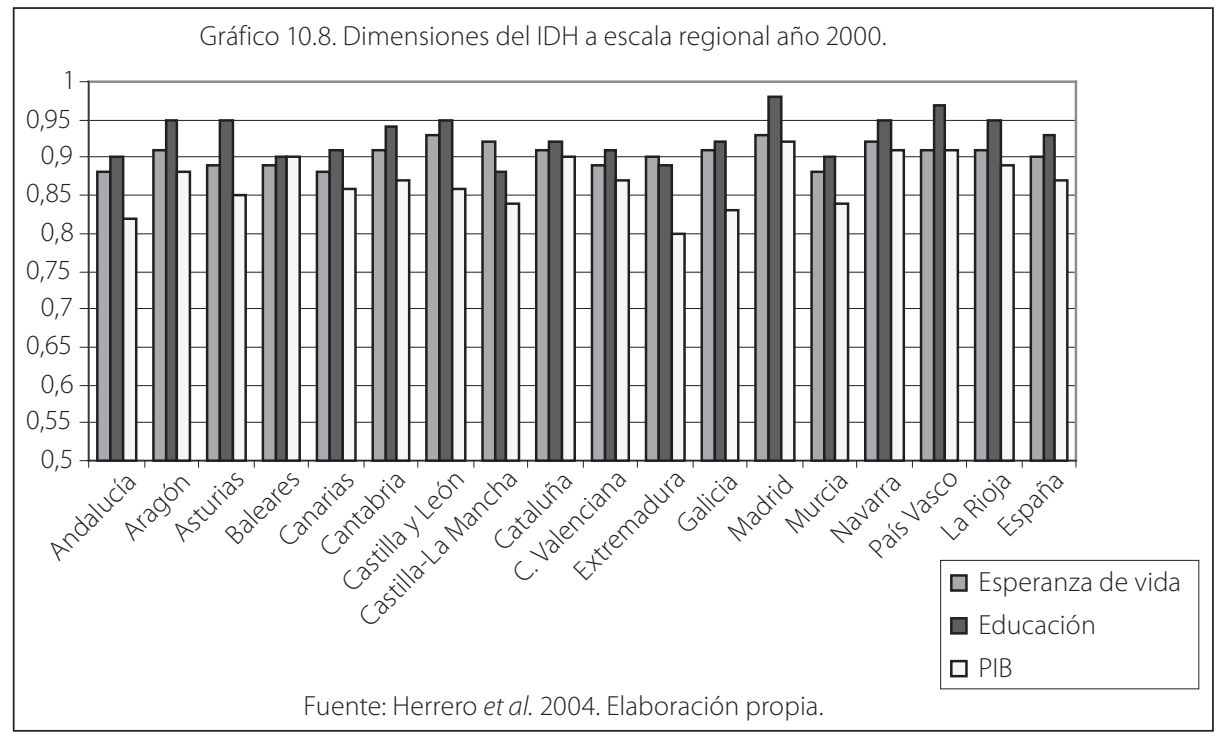

A partir de lo señalado podría hablarse de una cierta convergencia $\beta$. Aquellas regiones que partían de posiciones más retrasadas en términos de desarrollo humano han experimentado un crecimiento más rápido que las más desarrolladas, no solo por un relativamente mayor crecimiento de la renta, sino especialmente por la igualación en prestaciones sociales y en inversión en capital humano (Gráfico 10.9). Todo ello puede derivar en la mejoría de los niveles de satisfacción subjetiva revelada (felicidad), en particular cuando es producto de una etapa reciente para la que todavía no se ha generado un proceso de acomodación.

La valoración que estamos realizando considera las tendencias medias regionales pero oculta notables divergencias a escala microgeográfica. Tal y como se señalará en el capítulo relativo a Valores Económicos, existen al menos dos claras tendencias respecto al desarrollo socioeconómico en el conjunto gallego. De un lado, un área relativamente dinámica que agrupa a los municipios de mayor dimensión y al denominado eje urbano secundario, es decir, municipios de tamaño medio enlazados a los principales ejes de desarrollo. Del otro, nos encontramos con un amplio conjunto de municipios que se encuentran en un claro proceso de vaciamiento o envejecimiento poblacional, eminentemente rurales y agrarios y con un menor nivel de renta. Las consecuencias de esta doble dinámica del desarrollo socioeconómico tienen una clara traducción en la satisfacción subjetiva revelada (Pena y Sánchez, 2007). 

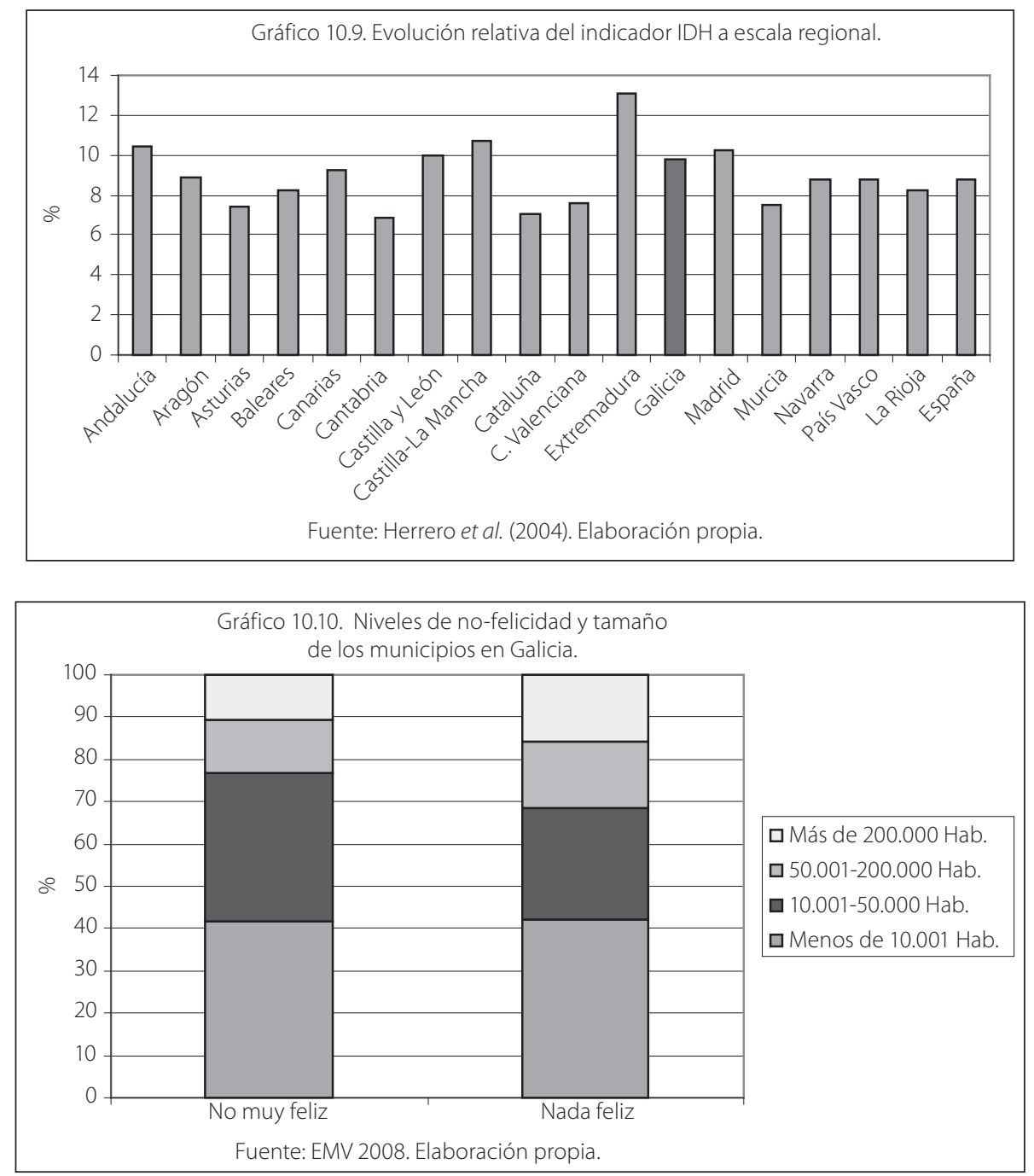

A modo de proxy, si analizamos la localización geográfica de aquellos que se manifiestan como poco o nada felices se observa que mayoritariamente se encuentran en municipios de menos de 50.000 y más de un 40\% en los de menos de 10.000 (Gráfico 10.10). Aunque se trata de un dato que presenta múltiples problemas en su interpretación, en especial si tenemos en cuenta las particularidades de la geografía y demografía gallegas, los municipios de menor dimensión poblacional son aquellos que carecen de condiciones de centralidad en términos christalerianos y coinciden con los menos desarrollados socioeconómicamente, envejecidos y con menor dotación de servicios sociales clave en el desarrollo humano (educación, sanidad...). 
Si trasladamos el análisis a escala individual, en línea con los resultados arrojados por la estimación de la función microeconométrica de la felicidad, existe una clara relación entre los niveles de felicidad de los individuos y su nivel de renta (Gráfico 10.11). Ahora bien, parece evidenciarse también una relación no lineal que estaría traduciendo los lógicos rendimientos marginales decrecientes de la renta. Es decir, incrementos en la renta suponen incrementos progresivamente menos que proporcionales en los niveles de felicidad. Las quintiles de mayor renta se manifiestan como más felices pero, al igual que en cualquier economía desarrollada, cuando el incremento general de la renta permite superar un determinado umbral de seguridad en los ingresos, sucesivas mejoras no tienen su traducción en elevaciones en los niveles de bienestar subjetivo y pueden llegar a ser irrelevantes. No obstante, conviene tener presente, tal y como han puesto de manifiesto los trabajos de Veenhoeven (2000), que las diferencias observadas en el ingreso se deben parcialmente al hecho de la relación positiva existente entre ingreso, salud y socialidad en las sociedades abiertas.

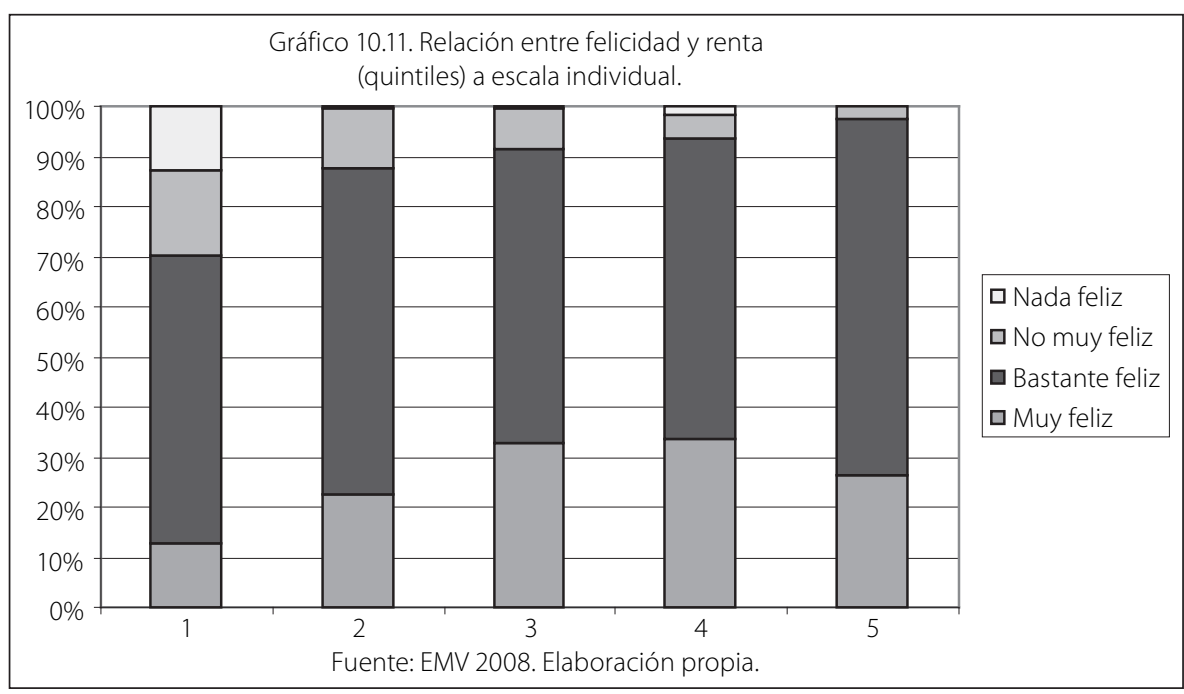

Centrándonos en la satisfacción económica de los gallegos (Gráfico 10.12), nos encontramos con algunas evidencias. En primer lugar, la población gallega ha experimentado en todo este largo período pequeñas variaciones, con lo que la aportación de esta variable a la evolución de la felicidad puede considerarse más limitada de lo que pudiese parecer en primera instancia. Se incrementa el posicionamiento en los puntos centrales de la distribución al mismo tiempo que se reduce el de aquellos que se muestran muy insatisfechos con la situación financiera del hogar. En segundo lugar, una vez más, una lectura agregada de los datos nos permitiría afirmar que la sociedad gallega se encuentra dentro de lo que podríamos denominar "sociedades satisfechas" ya que un 70\% de los encues- 
tados se posiciona en niveles superiores al 5, no obstante, si contrastamos los resultados con los de la satisfacción vital se observa claramente que esta última refleja resultados superiores. Esto es, tal y como se desprendía de la estimación de la función de felicidad y del análisis de la evolución de los niveles de renta e IDH, los determinantes de la felicidad, aunque influidos por el ingreso, parecen ir asociados a mejoras en otras dimensiones.

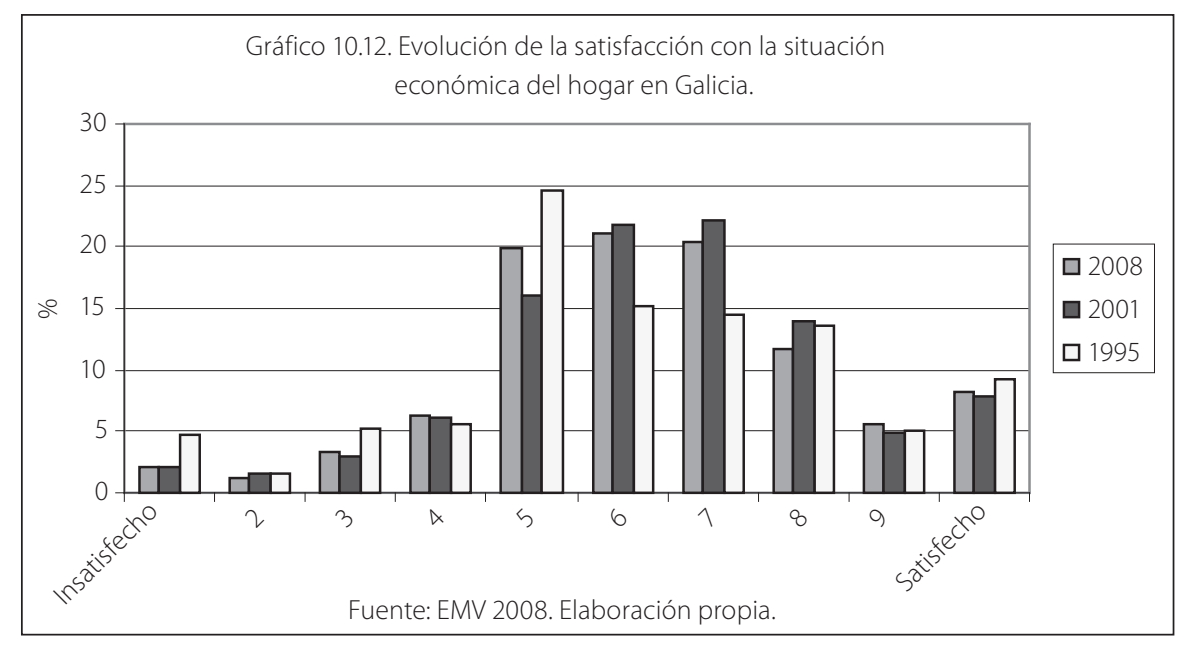

Finalmente, tal y como señalamos al referirnos a la paradoja de Easterlin, la interpretación de estas relaciones es extremadamente compleja. Nos encontramos con distintas tendencias dependiendo de culturas y países. Además, no pueden asociarse solo al ingreso sino que es preciso considerar el problema de la renta relativa, la desigualdad y particularmente el problema de la seguridad en esos ingresos (lo que sería traducible por el problema de la renta permanente). Junto a ello, es preciso considerar los procesos de acomodación a los períodos de crecimiento. Así, la valoración de un proceso de mejora del entorno socioeconómico puede ser especialmente sensible durante el mismo, para verse posteriormente minorada en la medida en que la población se acomoda a los nuevos estándares.

No obstante, no se puede perder de vista que la última oleada de la encuesta que sirve de base para este estudio ha sido realizada en la antesala de una crisis con importantes repercusiones socioeconómicas y, en el futuro, será esencial analizar el componente coyuntural y estructural de estas valoraciones. No en vano, la recesión que se evidenció especialmente tras la última elaboración de esta encuesta puede tener una fuerte repercusión en las valoraciones subjetivas por sus efectos sobre ingresos y empleo y seguridad en ambos. De hecho, puede hablarse de una cierta asimetría o de "efecto trinquete" en el sentido de que los individuos se adaptan a las nuevas situaciones rápidamente y las pérdidas en las mismas se ven reflejadas más fuertemente (Duesenberry, 1949). 


\subsubsection{Los "otros" determinantes de la felicidad}

Una vez discutido el papel de la renta como factor determinante de la felicidad, cabe completar el análisis ahondando en el estudio de los demás factores que, en mayor o menor medida, también se han revelado significativos: la salud, el entramado de relaciones sociales, la situación laboral, el nivel de estudios y el entorno político.

\section{La salud}

Tal y como observamos en la construcción de la función micro de la felicidad, la autovaloración del nivel de salud muestra una significativa correlación positiva y se integra en dicha función. En la valoración del bienestar subjetivo individual los gallegos otorgan un elevado peso a la percepción sobre su nivel de salud, de la misma manera que la propia valoración de la felicidad tiene un efecto sobre la percepción de ésta. Estamos, por tanto, ante una clara relación bidireccional.

Para el conjunto de la población encuestada en Galicia se aprecia un sensible proceso de mejora (Gráfico 10.13). Pese al envejecimiento poblacional que caracteriza la sociedad gallega, en torno a un 7\% de la población encuestada abandona las posiciones de regular o mala para incorporarse a las de buena o muy buena.

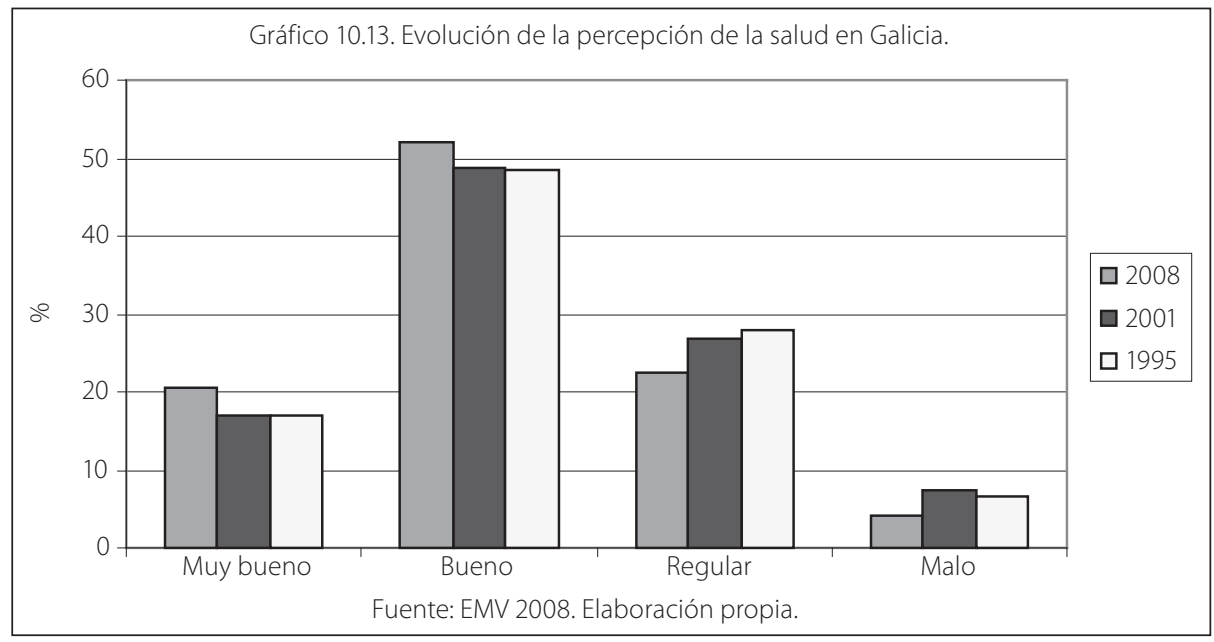

Si bien, en general, esta trayectoria es asimilable al conjunto español, los niveles de salud reflejados por los gallegos son ligeramente inferiores. Los factores que pueden estar detrás de esta leve diferencia pueden ser de muy diverso tipo, desde el mencionado envejecimiento poblacional, hasta las particularidades climáticas o incluso la mayor dificultad para la prestación de servicios sanitarios derivada de la dispersión demográfica. 
Ligada a la variable salud podemos analizar el papel de la variable edad como determinante de la felicidad (Gráfico 10.14). Si nos centramos en el grupo que se declara no feliz (no muy feliz y nada feliz) ${ }^{11}$ éste se incrementa de forma continua a medida que se aumenta la edad, hasta situarse próximo a un 15\% en el tramo superior de edad.

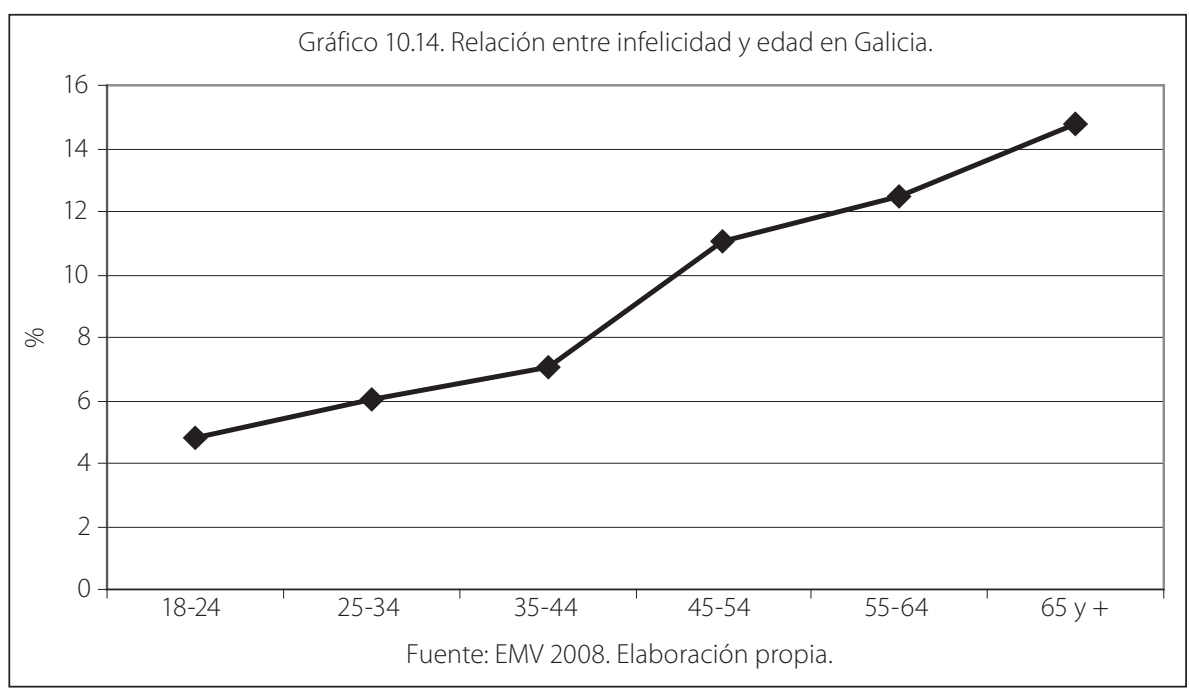

La tendencia general es suponer que los grupos de mayor edad son menos felices, en gran medida por la extensión de cierto culto a la juventud en las sociedades occidentales y, en parte, es así. No obstante, en la explicación no se puede ignorar un conjunto de circunstancias que, más allá de problemas de salud, van desde la reducción de ingresos a la reducción de la red personal de relaciones.

Las relaciones sociales

Al igual que la salud, el entramado de relaciones sociales tiene un efecto directo sobre el nivel de bienestar revelado. El mayor porcentaje de individuos que se manifiestan como nada felices o no muy felices se encuentra en aquellos grupos que carecen de un marco familiar, bien por viudedad, bien por ruptura de la relación previa. En los grupos de divorciados, separados y viudos se incrementa el porcentaje de nada felices o no muy felices (respectivamente $30,6,22,8$ y $24,8 \%$ ) frente a los porcentajes más reducidos que se encuentran en aquellos que disponen de pareja estable, esto es, casados y con pareja $(6,1$ y $6,3 \%$ respectivamente). Por tanto, este efecto está especialmente ligado a la pérdida de una red familiar más que a la no disposición de la misma. Esto es, los solteros, aunque se muestran algo más insatisfechos que aquellos que disponen

11 Calificamos como grupo de no felices al agregado de aquellos que se definen como poco o nada felices. 
de pareja estable, se encuentran considerablemente por encima de aquellos que han perdido esa red de relaciones ${ }^{12}$.

Como se observa en el Gráfico 10.15, las diferencias en la situación familiar pueden ocasionar una enorme variación en la felicidad, por encima de cambios en el nivel de ingresos. Estos efectos son especialmente significativos en el caso de divorcios o viudedad por lo que supone de reconfiguración de la estructura de relaciones personales. En este sentido, lo aparentemente relevante es la calidad y estabilidad de las relaciones y no su forma, dado que no existe diferencia entre matrimonio y parejas de hecho.

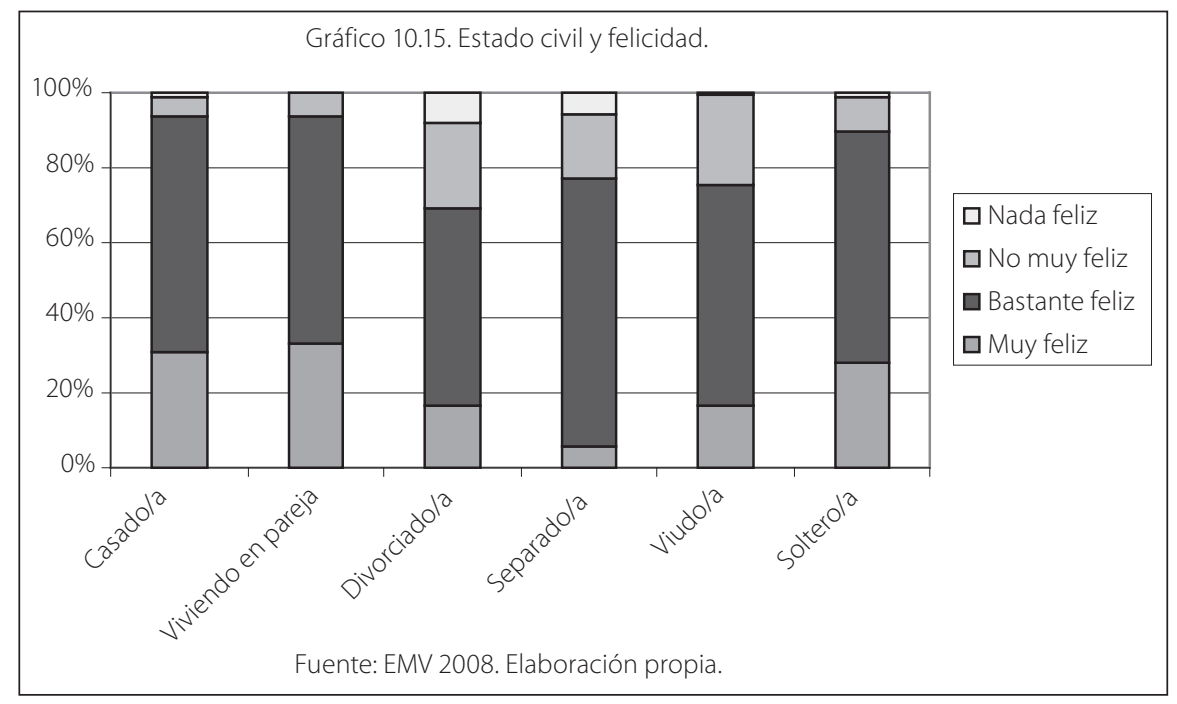

Indudablemente, el hombre es un ser social. Formar parte de una familia, un grupo o un colectivo contribuye de forma decisiva a la felicidad, aportándole una identidad personal. Para el caso gallego, la relación interpersonal que se revela más importante es el matrimonio y la familia. Este hecho es compatible con la hipótesis según la cual el matrimonio aporta desde ventajas de mercado, hasta efectos benéficos en términos de morbidad, salud mental, etc., y, muy especialmente, en términos de felicidad o satisfacción subjetiva revelada, relación que persiste incluso si se controlan variables como la edad, los ingresos o la educación.

La calidad de nuestro entorno social más amplio o capital social se manifiesta como crucial para crear un marco de seguridad y bienestar personal. Pese a que este es un aspecto difícilmente evaluable, podemos encontrar un cierto vínculo con las respuestas relativas a la confianza social generalizada, cuyos niveles presentan correlaciones positivas con la satisfacción subjetiva revelada.

12 El caso de los solteros reviste otras características, dado que se asocian mayoritariamente con población juvenil. 
Si recurrimos a indicadores indirectos sobre la incidencia de las dotaciones individuales de capital social en el nivel de satisfacción subjetiva, otro de los aspectos que se desprenden de los datos manejados, es el elevado consenso sobre el modelo de vida en la sociedad gallega. La práctica totalidad de los entrevistados sitúa los valores ligados a los lazos familiares y de amistad muy por encima de cualquier otro. Además, los individuos que dan una mayor importancia a su red de lazos más directos — bonding social capital_ (familia y amigos) (gráficos 10.16 y 10.17) se manifiestan considerablemente más felices. Esto último, ya se desprendía del análisis de regresión, que identificaba estas variables como altamente significativas. Además, a lo anterior hay que añadir que el peso que se le otorga al disfrute del tiempo libre o su valoración como objetivo vital resultaba crucial. Este rasgo es un claro indicador del establecimiento de una sociedad del ocio.

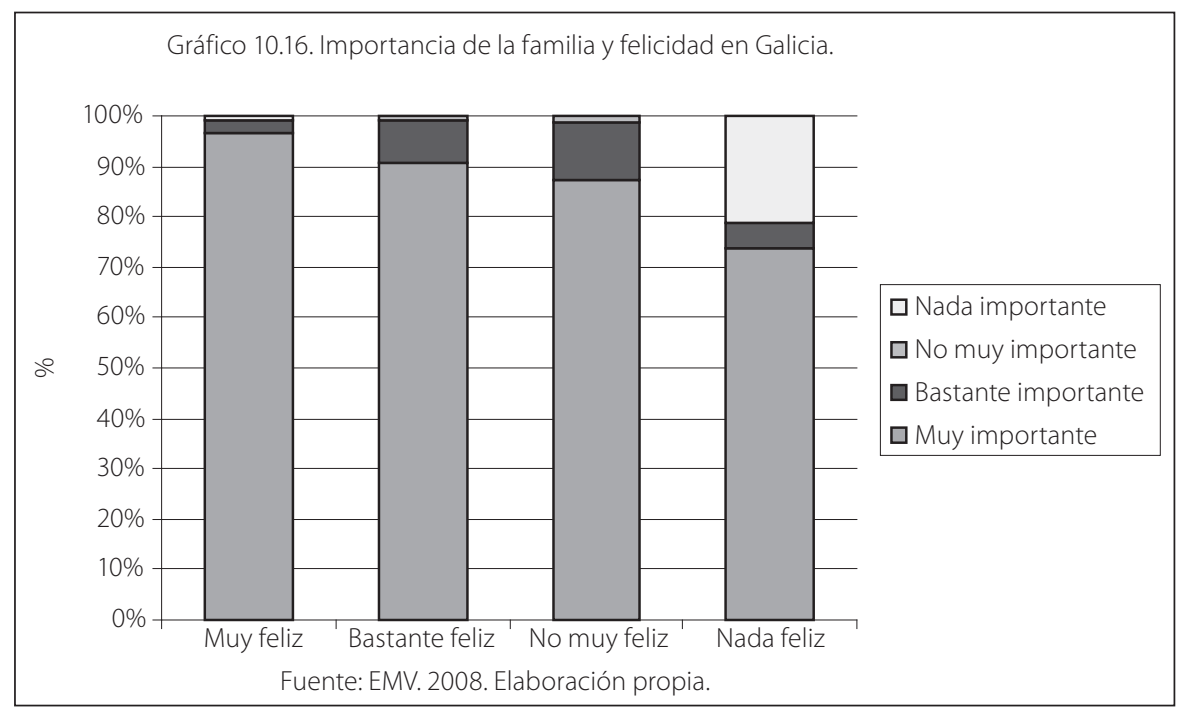

En sentido inverso, los datos disponibles muestran que la práctica totalidad de aquellos que se declaran como no felices se sitúan entre los que consideran poco o nada importante la familia. Del mismo modo, la amistad y el tiempo libre (Gráfico 10.18) aparece como un valor menos relevante para aquellos que se declaran poco felices.

En consonancia con lo apuntado en la introducción al problema de la felicidad, de las anteriores consideraciones se infiere que ésta se encuentra ligada al problema de la sociabilidad del ser humano, es decir, lejos de depender exclusivamente de bienes materiales se asocia igualmente a los denominados bienes relacionales. Ahora bien, como rasgo distintivo de la sociedad gallega, al igual que las sociedades del sur de Europa de tradición católica, cabe señalar que concede una gran relevancia a la familia como base del comportamiento y felicidad individual, hasta el punto 
de que podríamos afirmar que la felicidad o satisfacción se ajusta en terminología beckeriana a una función de producción colectiva.
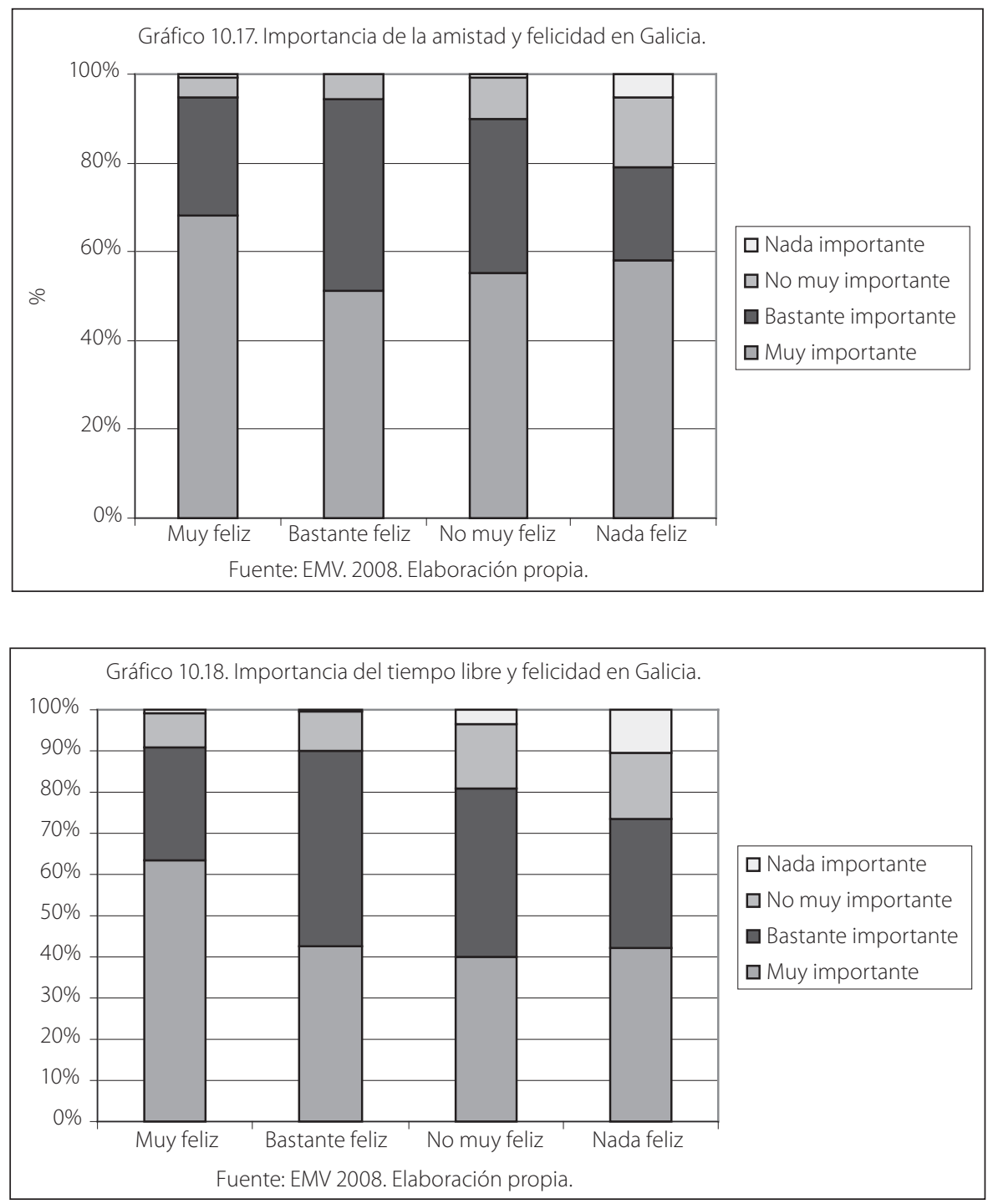

Además de las anteriores variables, la felicidad también depende de nuestro ser interior y de nuestra filosofía de vida, es decir, los valores de los individuos influyen fuertemente en los niveles de satisfacción vital. En esta línea, Rojas (2007) argumenta que la relación ingreso felicidad es contingente de los valores que asuman las personas. Desde su perspectiva, el ingreso es relevante para la felicidad en aquellas personas en las que predominan los valores orientados "hacia fuera", mientras que su relevancia es casi nula en aquellos con valores "hacia adentro". Estos últimos basan su felicidad en factores distintos a la adquisición 
de bienes y servicios. De esta manera, buena parte de los factores explicativos del bienestar dependen de los valores de cada sujeto. En este sentido, en el caso de los gallegos, la familia y la red de amistad, así como el cultivo de un tiempo para el disfrute personal resultan, como ya hemos señalado, determinantes.

\section{Situación laboral}

Existe un claro vínculo entre el nivel de bienestar y la situación laboral que puede presentarse por diversas vías. En primer lugar, está el efecto de la incorporación al mercado de trabajo, esto es, la actividad o inactividad del entrevistado. En segundo lugar, la disposición o no de empleo y, finalmente, el nivel de satisfacción generada por el propio trabajo (Gráfico 10.19).

De acuerdo con los datos, en el colectivo que comprende los que se declaran menos felices tienen un elevado peso los individuos que se sitúan al margen del mercado de trabajo (amas de casa y pensionistas) y los que se encuentran en situación de búsqueda de empleo. La razón reside en que la incorporación al mercado de trabajo supone no solo una mayor independencia económica, sino un cauce de realización personal y la adquisición de una importante red de capital social (bridging). Además, los ocupados perciben que están contribuyendo a la sociedad en un sentido amplio, de esta manera el trabajo no solo proporciona ingresos sino un sentido a la propia vida. El desempleo junto a una pérdida de ingresos, supone también un deterioro de la red de relaciones personales y de significado de la propia existencia. Por consiguiente, se corrobora claramente que los costes de la no incorporación al mercado de trabajo, no son exclusivamente económicos, sino también psíquicos y sociales.

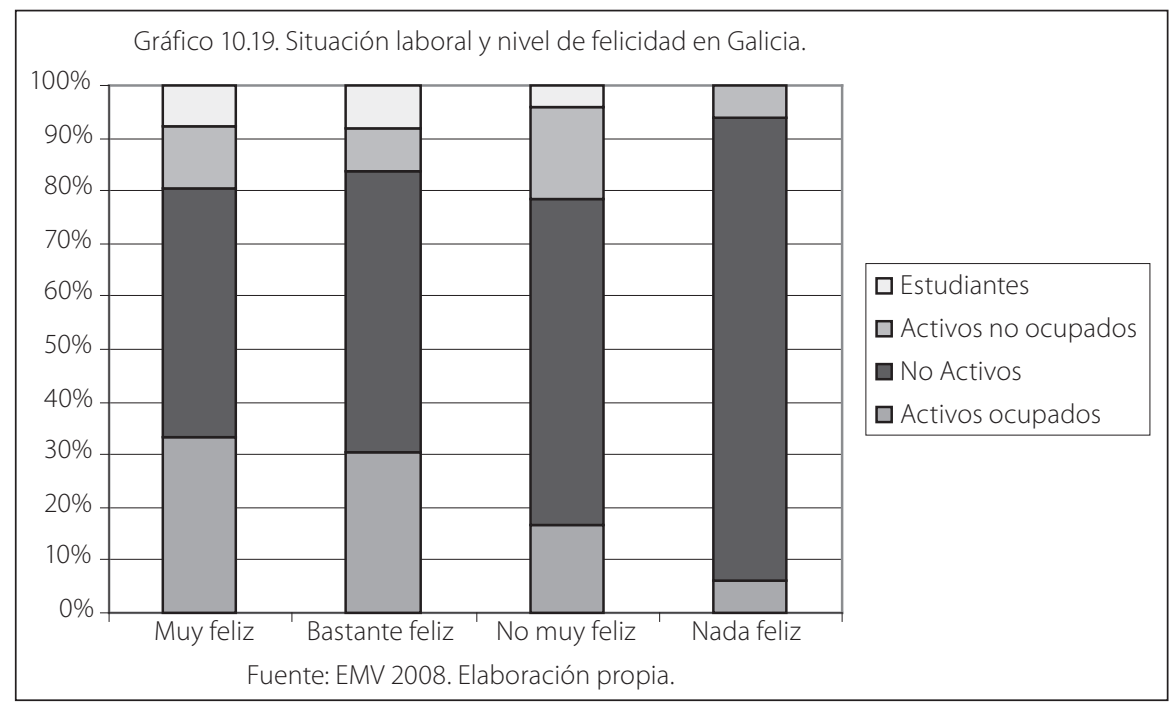

En el caso de los que tienen trabajo, el temor a la pérdida del mismo puede suponer una reducción significativa de la felicidad. Así, en situaciones de rece- 
sión en las que se produce una elevación de los niveles de desempleo, lo lógico es que disminuyan los niveles de satisfacción subjetiva revelada.

En consonancia con lo ya señalado, los no activos son el grupo menos feliz, seguidos del grupo de activos no ocupados y los ocupados. El subgrupo de los estudiantes debe ser tratado aparte, dado que es todavía ajeno al mercado y se encuentra en una fase vital diversa (población juvenil dependiente).

Aunque algunos estudios previos (Frey y Stutzer, 2000) no detectaron una influencia significativa del tipo de empleo sobre los niveles de satisfacción, en nuestro caso, sin embargo, recurriendo a la estratificación presentada por Piore (1971), se obtiene alguna evidencia en sentido contrario. El grupo primario, que incluye a aquellos individuos de elevada cualificación, conductas directivas y muy alta estabilidad laboral e ingresos, presenta un mayor nivel de satisfacción subjetiva. El primario inferior engloba a aquellos individuos que aun contando con elevada cualificación realizan tareas intermedias de conducta consuetudinaria con menor nivel de ingresos, pero igualmente con notable estabilidad laboral, muestra una leve menor satisfacción. Finalmente, el secundario que representa el estrato de trabajadores de baja cualificación, bajas remuneraciones y poca estabilidad, con conductas altamente dependientes, es el grupo que se manifiesta menos feliz (Gráfico 10.20).

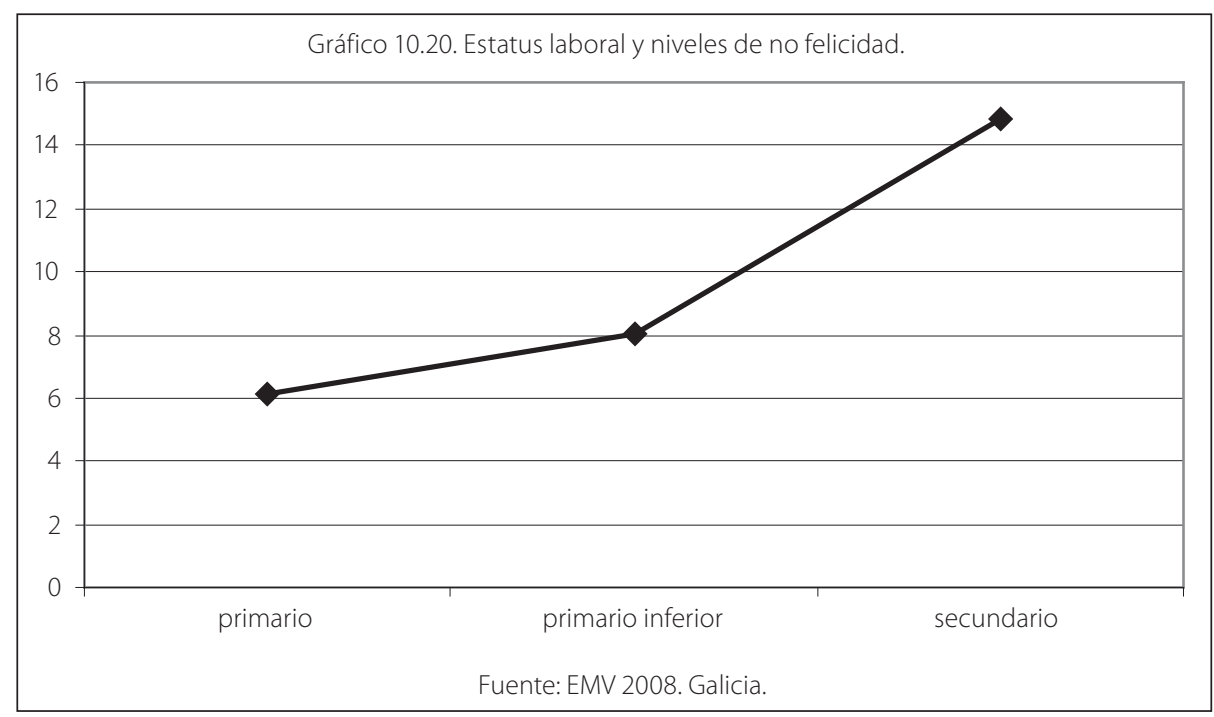

Nivel de estudios

Otra de las variables cuya influencia cabe analizar es la formación. La dotación de capital humano, por diversas vías (ingreso, situación laboral, capital social...) guarda una clara relación directa con la satisfacción subjetiva revelada. Si se observa la composición del colectivo de no felices (no felices y no muy felices) atendiendo al nivel de estudios (Gráfico 10.21), se aprecia una tendencia descen- 
dente a medida que aumenta el nivel de formación, siendo únicamente un 5\% de este colectivo, individuos con estudios universitarios.

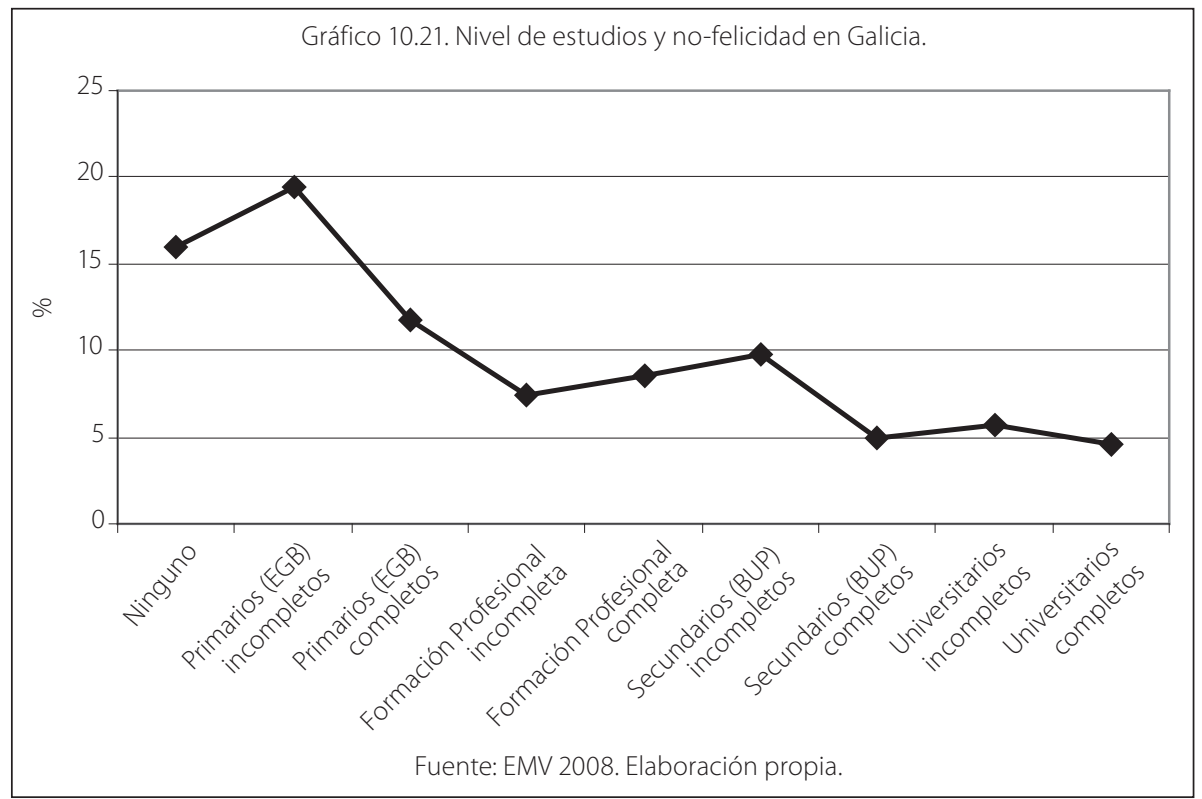

\section{Entorno político}

La felicidad también depende de la calidad de gobierno y el entorno del ejercicio de la actividad política. Bajo el concepto de entorno político se encuentra un complejo entramado de relaciones: la fortaleza del estado de derecho, la estabilidad y ausencia de violencia, la representatividad y estabilidad política, la ausencia de corrupción y la eficacia del sistema legislativo.

Hirschman (1989) ya planteaba la hipótesis de que tener opiniones o, mejor dicho, llegar a tenerlas y expresarlas mediante un proceso de información, deliberación y discusión, es uno de los factores determinantes de la felicidad personal. Por su parte, Frey y Stutzer (2000) han comprobado la validez de esta tesis para el caso suizo, dada su característica democracia directa.

En lo que hace referencia a la libertad política, cuanto menos coercitivo sea un sistema político y mayores sean las libertades individuales y políticas mayor es el nivel de felicidad. De hecho, en algunos casos las correlaciones han revelado niveles de significatividad próximos a los de la prosperidad económica. Un sistema político democrático en el que se garantizan los derechos fundamentales favorece tanto la extensión de los sentimientos de respeto personal y, a largo plazo, la noción de dominio o control sobre su propia vida, que resulta determinante sobre el nivel de felicidad.

En el mismo sentido, el concepto de capacidades al que ya se aludió anteriormente puede ser también traducido en términos de libertad. Concretamente, Sen 
(1999) considera que el desarrollo humano puede ser expresado como una forma de libertad positiva, esto es, capacidad para la humanización o crecimiento en libertad individual. Tal y como se visualiza en el Gráfico 10.22, en el caso gallego observamos un crecimiento del número de personas que tienen sensación de una mayor libertad y control sobre su propia vida.

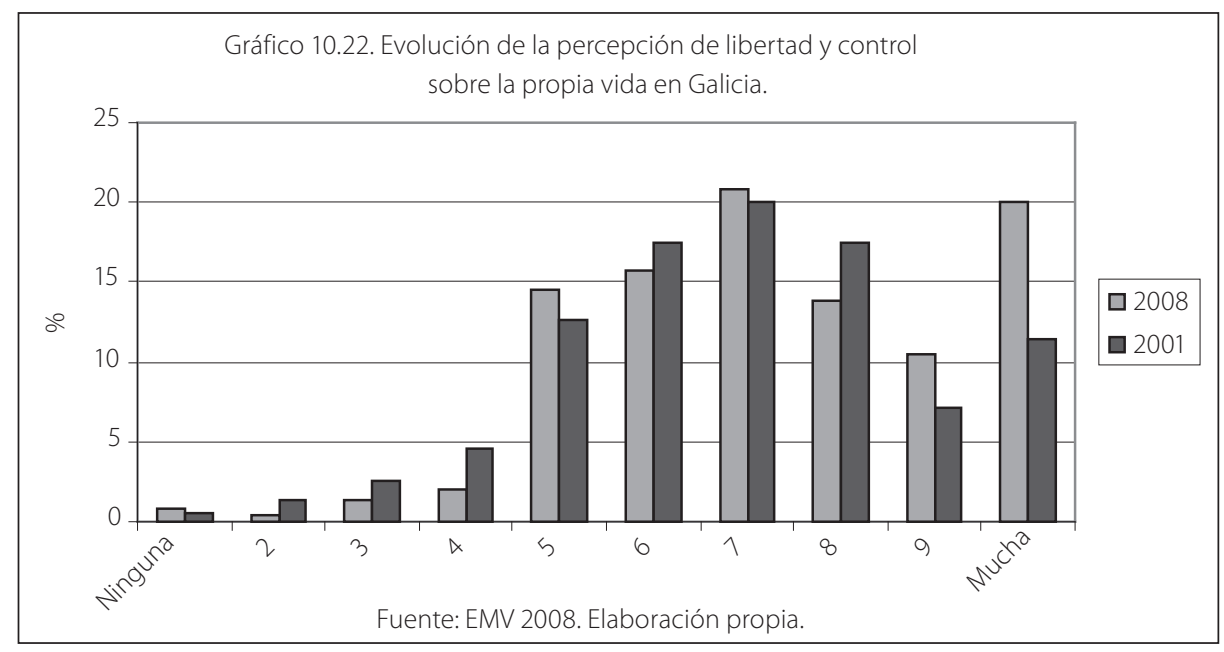

Junto a esto, cabe destacar que no existen grandes diferencias entre los que revelan percibir escasa libertad, tan solo leves reducciones, aunque relevantes si tenemos en cuenta el período al que se refiere el gráfico (2001-2008). De todos modos lo más llamativo es el elevado porcentaje de la población (prácticamente un $45 \%$ ) que se sitúa decididamente entre aquellos que perciben una elevada libertad y control sobre su vida (por encima del nivel de 7). Además, si se comparan estos datos con el conjunto de España, se verifica que la población gallega parece sentir un mayor control sobre su propia vida que la media española.

\subsection{CONCLUSIONES}

En el presente trabajo se replantea el problema de la felicidad en el ámbito de la Socioeconomía y se revisan las principales aportaciones de la denominada Happiness Economics con el objeto de contrastarlas con los resultados de la Encuesta Mundial de Valores en Galicia. En concreto, la investigación llevada a cabo viene a confírmar algunos de los presupuestos básicos del dicho paradigma.

Por una parte, el concepto de felicidad, entendido como la satisfacción subjetiva revelada por los propios individuos, es una aproximación válida para la valoración de la evolución de un ámbito socioeconómico concreto.

Por otro lado, la felicidad responde a cambios más complejos que los originados por la simple elevación de los niveles de renta. Esta constatación, entre otras cosas, cuestiona las perspectivas centradas en el binomio ingreso-bienestar que 
caracterizan buena parte de las propuestas de la política económica que sitúan al crecimiento económico como prioridad absoluta.

En este sentido, la paradoja de Easterlin (la ausencia de un vínculo entre incremento de la renta per cápita y evolución de la satisfacción subjetiva global), pone de manifiesto el carácter complejo de los determinantes de esta variable, en la que los bienes relacionales (redes de relaciones sociales), las dimensiones valorativas o axiológicas (valores personales) y el desarrollo humano en general parecen ser más determinantes que el mismo ingreso.

El estudio descriptivo de los datos de la EMV en Galicia refleja un notable incremento de los niveles de satisfacción subjetiva en la sociedad gallega en los últimos veinte años. Aunque a primera vista estos avances pueden asociarse a la elevación del nivel de renta, el análisis empírico desarrollado y plasmado en la estimación de una función de los determinantes de la felicidad permite verificar que la evolución del bienestar subjetivo revelado por la sociedad gallega presenta una causalidad más amplia.

En términos generales, se puede afirmar que la sociedad gallega solo se acomoda parcialmente a la paradoja de Easterlin. Ahora bien, en línea con las conclusiones de Easterlin, el ingreso en la función de felicidad de los gallegos desempeña un papel secundario y subjetivo, al tiempo que se revelan como muy importantes las variables asociadas a los bienes relacionales. De hecho, las mejoras observadas en Galicia en los indicadores de desarrollo humano (salud, educación e ingreso), es decir, las capacidades (o capabilities en la terminología de Sen), resultan tener más poder explicativo que los aumentos de la renta, tal y como postula la Economía Humanista.

Los resultados del presente trabajo también permiten hablar de cierta convergencia, ya que Galicia, partiendo de posiciones más retrasadas en términos de desarrollo humano, experimentó un crecimiento más rápido que otras regiones más desarrolladas, no solo por un relativamente mayor crecimiento de la renta, sino especialmente por la igualación en prestaciones sociales y en inversión en capital humano. Este hecho contribuiría a explicar la mejoría de los niveles de satisfacción subjetiva revelada (felicidad) de los gallegos, en particular, teniendo en cuenta que es producto de una etapa reciente para la que aún no se generó un proceso de acomodación.

Globalmente y optando por una vía negativa, los factores que parecen determinantes de una situación personal de menor satisfacción revelada (poco o nada felices) son fundamentalmente los bajos ingresos, la carencia de un marco relacional tanto familiar como social, el binomio salud-edad y la precariedad laboral (trabajos de nivel secundario). Además, para el conjunto de Galicia estos trazos se concentran en las zonas menos desarrolladas de forma que, también aquí (al igual que se identifica una doble dinámica del desarrollo socioeconómico a escala 
municipal), puede hablarse de una doble dinámica en la satisfacción subjetiva de los gallegos.

En definitiva, los resultados de la presente investigación permiten afirmar que, en consonancia con el señalado por Ryan y Deci (2001), evitar la pobreza, vivir en un país desarrollado y tener objetivos vitales no directamente relacionados con logros materiales, está asociado a mayores niveles de felicidad y que, a partir de cierto umbral, los incrementos de renta tienen escasa traducción en los niveles de bienestar subjetivo revelado.

\subsection{REFERENCIAS BIBLIOGRÁFICAS}

Ahuvia, A. y Friedman, D. A. (1998): "Income, consumption, and subjective well-being", Journal of Macromarketing 18 2: 153-168.

Argyle, M. (2002): The psychology of happiness. Londres, Routledge.

Bruni, L. (2004): History of Happiness in Economics. Londres, Routledge.

Bruni, L. y Porta, P. (2005): Economics and happiness. Framing the analysis. Oxford, Oxford University Press.

Di Tella, R., Macculloch, R. y Oswald, A. (1999): The macroeconomics of happiness, Working paper, Center for European Integration Studies. University of Warwick.

Duesenberry, J. S. (1949): Income, Saving and the Theory of Consumer Behavior. Cambridge, MA, Harvard University Press.

Easterlin, R. A. (1974): "Does Economic Growth Improve the Human Lot?" en Paul A. David y Melvin W. Reder (Eds.), Nations and Households in-Economic Growth: Essay in Honor of Moses Abramovitz. Nueva York: Academic Press.

Easterlin, R. A. (1995): "Will raising the incomes of all increase the happiness of all?", Journal of Economic Behavior and Organization 27 (1995): 35-47.

Easterlin, R. A. (2001): "Income and happiness: towards a unified theory", Economic Journal 111: 465-484.

Easterlin, R. A. (2002): Introduction to Happiness in Economics. Cheltenham, Edward Elgar.

Esteve Mora, F. (2000): Bienestar y crisis del Estado del Bienestar. Elementos para una economía de la felicidad en R. Muñoz de Bustillo (Ed.), El Estado de Bienestar en el cambio de siglo. Madrid, Alianza.

Frey, B. y Stutzer, A. (2000): "Happiness, economy and institutions", Economic Journal 110: 918-938.

Frey, B. y Stutzer, A. (2001): Happiness and Economics. Princeton, Princeton University Press.

Frey, B. y Stutzer, A. (2002): "What can economists learn from happiness research?", Journal of Economic Literature XL: 402-435.

Gradin, C., Del Rio, C. y Cantó, O. (2006): La distribución de la renta en Galicia. A Coruña, CIEF-Fundación Caixa Galicia. 
Herrero, C., Soler, A. y Villar, A. (2004): Capital humano y desarrollo humano en España, sus comunidades autónomas y provincias Valencia, Bancaja.

Hirschman, A. O. (1982): Shifting involvements, Private interest and Public Action. Princeton, Princeton University Press.

Hirschman, A. O. (1989): "Having opinions-one of the elements of wellbeing", American Economic Review. Papers and proceedings, 79, 2: 75-79.

Inglehart, R. (1996): "The diminishing utility of economic growth", Critical review, 10, 4: 509-531.

Inglehart, R. (2004): Subjective Well-Being Rankings of 82 Societies. www.worldvaluessurvey.org.

Kahneman, D. (1999): Objective happiness, en Kahneman, D., Diener, E., y Schwarz, N. (Eds.), Well-Being: The Foundations of Hedonic Psychology. Nueva York: Russell Sage Foundation.

Kahneman, D., Diener, E., y Schwarz, N. (Eds.) (1999): Well-being: The foundations of hedonic psychology. Nueva York: Russell Sage Foundation.

Layard, R. (2003): Happiness: Has social science a clue? Three Lectures. First lecture: What is Happiness?; second lecture: Income and Happiness: Rethinking Economic Policy; third lecture: What Would Make a Happier Society. Lionel Robbins Memorial Lectures.

Layard, R. (2005): Happiness. Lessons from a New Science. Londres, Penguin Books.

MacIntyre, A. (2001): Tras la virtud, Barcelona, Crítica.

Mill, J. S. (1859) [1991]: On Liberty, J. Gray y G. W. Smith (Eds.). Londres: Routledge. Nussbaum, M. C. y Sen, A. K. (1993): The Quality of Life. Oxford, Clarendon Press.

Putnam, R. D. (2000): Bowling alone: The collapse and revival of American community. Nueva York, Simon \& Schuster.

Oswald, A. J. (1997): "Happiness and Economic Performance", Economic Journal, Royal Economic Society, 107(445): 1815-31.

Peiró Jiménez, A. (2004): "Condiciones socioeconómicas y felicidad de los españoles", ICE, 816: 179-194.

Pena López, J. A. y Sánchez Santos, J. M. (2007): “Organización espacial de la actividad económica y desarrollo local: evidencia para el caso gallego", Revista Galega de Economía, 16 (2).

Piore M. J. (1971): "The dual labor market: theory and implications" en Gordon, D. M. (Ed.), Problems in Political Economy: An Urban Prospective. Lexington. Mass., D. C. Heath.

Prada Blanco, A. y Lago Peñas, S. (2009): Galicia, unha economía europea. Vigo, Galaxia.

Rawls, J. (1971): A Theory of Justice. Cambridge, MA, Harvard U.P. 
Ryan, R. y Deci, E. (2001): "On happiness and human potentials: A review of research on hedonic and eudaimonic wellbeing", Annual Review of Psychology, 52: 141-166.

Rojas, M. (2007): "The complexity of well-being: A life satisfaction conception and a domains-of-life approach" en I. Gough y A. MacGregor (Comps.) Researching wellbeing in developing countries. Cambridge University Press.

Rojas, M. (2009): "Economía de la felicidad. Hallazgos relevantes respecto al ingreso y bienestar", El Trimestre Económico, 303: 537-573.

Sánchez, P., Vaamonde, A. y García, X (2007): A pobreza en Galicia. Santiago de Compostela, Sotelo Blanco.

Sen, A. K. (1999): Development as freedom. Nueva York, A. Knopf, Inc./Random House Inc. (edición en castellano: Desarrollo y Libertad, Ed. Planeta, Barcelona, 2000).

Stutzer, A. (2004): "The role of income aspirations in individual happiness", Journal of Economic Behavior and Organization, 54 (1): 89-109.

Veenhoven, R. (1984): Conditions of happiness. Dordrecht, Kluwer, University.

Veenhoven, R. (1993): Happiness in nations: Appreciation of life in 56 nations. Rotterdam: Erasmus.

Veenhoven, R. (2000): "The Four Qualities of Life. Ordering Concepts and Measures of the Good Life", Journal of Happiness Studies 1: 1-39.

Veenhoven, R. (2001): What We Know about Happiness?, Erasmus University Rotterdam, working paper.

WHOQOL Group (1993) "Study protocol for the World Health Organization project to develop a quality of life assessment instrument" (WHOQOL), Quality of Life Research, 22: 153-159. 